NBER WORKING PAPER SERIES

\title{
COMPARATIVE ANALYSIS OF LABOR MARKET OUTCOMES: LESSONS FOR THE US FROM INTERNATIONAL LONG-RUN EVIDENCE
}

\author{
Giuseppe Bertola \\ Francine D. Blau \\ Lawrence M. Kahn \\ Working Paper 8526 \\ http://www.nber.org/papers/w8526 \\ NATIONAL BUREAU OF ECONOMIC RESEARCH \\ 1050 Massachusetts Avenue \\ Cambridge, MA 02138 \\ October 2001
}

This work is part of the Sustainable Employment Initiative, jointly sponsored by the Russell Sage Foundation and the Century Foundation. Portions of the paper were written while Blau and Kahn were Visiting Scholars at the Russell Sage Foundation. We are grateful to Olivier Blanchard and Justin Wolfers for making their macroeconomic data set available, and to Justin Wolfers for his help in assembling and using the data; to David Neumark for providing us with demographic data; and to Jonas Pontusson and David Rueda for their help in obtaining union density and unpublished OECD earnings data. We are indebted to Julian Messina, Abhijay Prakash, Andre Souza, and especially Thomas Steinberger for excellent research assistance. For helpful comments and suggestions we thank Alan Krueger, Lisa Lynch, David Weiman, other participants in the Russell Sage/Century Foundation Conference on Sustainable Employment (Amelia Island, Florida, January 26-28), Olivier Blanchard, Pierre Cahuc, and especially Robert Solow. The views expressed herein are those of the authors and not necessarily those of the National Bureau of Economic Research.

(C) 2001 by Giuseppe Bertola, Francine D. Blau and Lawrence M. Kahn. All rights reserved. Short sections of text, not to exceed two paragraphs, may be quoted without explicit permission provided that full credit, including $\odot$ notice, is given to the source. 
Comparative Analysis of Labor Market Outcomes:

Lessons for the US from International Long-Run Evidence

Giuseppe Bertola, Francine D. Blau and Lawrence M. Kahn

NBER Working Paper No. 8526

October 2001

JEL No. J5, J6, E0

\begin{abstract}
$\underline{\text { ABSTRACT }}$
We analyze a 1960-96 panel of OECD countries to explain why the US moved from relatively high to relatively low unemployment over the last three decades. We find that while macroeconomic and demographic shocks and changing labor market institutions explain a modest portion of this change, the interaction of these shocks and labor market institutions is the most important factor explaining the shift in US relative unemployment. Our finding of the central importance of these interactions is consistent with Blanchard and Wolfers (2000). We also show that, controlling for country- and time-specific effects, high employment is associated with low wage levels and high levels of wage inequality. These findings suggest that US relative unemployment has fallen in recent years in part because its more flexible labor market institutions allow shocks to affect real and relative wages to a greater degree than is true in other countries. Disaggregating, we find that the employment of both younger and older people fell sharply in other countries relative to the United States since the 1970s, with much smaller differences in outcomes among the prime-aged. In the late 1990s, the US had lower unemployment than our models predict, suggesting exceptionally favorable recent US experience.
\end{abstract}

Giuseppe Bertola

Department of Economics

European University Institute

San Domenico di Fiesole I-50016

Florence, Italy

and CEPR

Lawrence M. Kahn

Departments of Labor Economics and Collective Bargaining

Cornell University

Ithaca, NY 14853

and CESifo
Francine D. Blau

Department of Labor Economics

Cornell University

Ithaca, NY 14853

NBER, CILN, and CESifo

fdb4@cornell.edu 


\section{Introduction}

The contrast between the labor market performance of the United States and most other advanced economies over the last thirty years has been striking. During the 1970-75 period, the unemployment rate was 5.4\% in the United States but under 3\% in: Australia, Austria, Belgium, France, West Germany, Japan, the Netherlands, Norway, New Zealand, Spain, Sweden, and the United Kingdom. Among major Western countries, Italy's unemployment rate of $4.3 \%$ was the only one close to the US unemployment level. ${ }^{1}$ American observers pondered the explanation for the persistently higher US unemployment levels. This concern was well captured in the title of an influential paper about the US experience that appeared at this time, "Why is the Unemployment Rate So High at Full Employment?" (Hall 1970). High turnover rates of US workers which resulted in high quit rates accompanied by spells of unemployment were seen as an important part of the story (Flanagan 1973). ${ }^{2}$

Indeed, one does not need to spend much time in a library to find statements of fact and theory extolling Europe and Japan as examples for American labor markets during that period. So, for example, Thurow (1985) noted that "What is considered full employment in the United States is far above what is considered full employment in any other industrial country, and since World War II American unemployment has been far above that in Japan.” (pp. 9-10). Thurow and Heilbroner (1981) pointed to a number of features of European economies which in their view contributed to this difference: "European nations have generally gone much further than we have in providing labor exchanges or in seeking to remedy structural unemployment, and they have been willing to accept a higher level of inflation as a lesser evil than a high level of unemployment. This superior performance has worsened considerably in the last few years, but Europe is still ahead of the United States in its anti-unemployment programs." (p. 50). And

\footnotetext{
${ }^{1}$ These figures are computed from the dataset prepared and generously made available by Blanchard and Wolfers (2000), which we further analyze and extend below.

${ }^{2}$ While we do not emphasize views of unemployment as a frictional phenomenon below, that component of overall unemployment is indeed likely to be strongly affected by labor market institutions. Union coverage has been found to greatly lower workers' turnover propensities (Freeman 1980), employment protection mandates are positively associated with worker job tenure (Bertola 1998), and regional wage differentials and labor mobility are much more important in the US, likely reflecting at least in part its decentralized wage-setting processes (Bertola 1999a).
} 
Kaufman (1979) argued that “...the generosity of unemployment insurance systems abroad may not significantly increase foreign unemployment rates in the 'open' sector because layoffs and discharges are greatly inhibited. In the United States, however, these benefits do increase the unemployment rate significantly." (p. 168).

Since the early 1970s, after two oil crises, vastly increased globalization, and rapid technical change, the unemployment position of the United States and the other Western countries has dramatically reversed. By 1999, the US unemployment rate had fallen to $4.2 \%$, and was as low as 3.9\% as of September 2000 (USBLS web site). In contrast, unemployment had risen sharply in virtually every other Western country. By 1999, unemployment averaged 9.2 percent in the European Union and had been at such levels for nearly 20 years (OECD 1999, 2000), with particularly high levels in Finland (10.3\%), France (11.3\%), Italy (11.4\%), and Spain $(15.9 \%)$.

By the 1980s and 1990s, it was European observers who searched for explanations for persistently high European unemployment rates. Increasing labor market flexibility_freeing up the forces of supply and demand to determine pay and employment and diminishing the role of union contracts or government regulations - was seen by some as the key to lowering European unemployment (OECD 1994b). Interestingly, this reasoning implies that the type of high worker mobility in the United States that had been a concern in the earlier period could now be viewed as one component of the more flexible US labor markets which, taken as a package, were associated with lower unemployment rates. Others however doubt that greater flexibility would in fact achieve lower unemployment, pointing instead to low levels of demand for labor as the culprit in Europe's higher unemployment (Glyn and Salverda 2000).

Following Blanchard and Wolfers (2000) and other recent contributions, this paper examines the role of labor market flexibility and labor demand factors in determining the divergent employment experience of the US and other industrial countries. There is, however, another side to this comparison. While the United States has fared well in recent years in creating jobs and maintaining low unemployment, its wage levels have deteriorated relative to 
those overseas. And wage inequality, always higher in the United States than in other advanced countries, has increased more sharply than it has elsewhere. Between 1979-81 and 1994-98, median real weekly earnings of male full-time workers in the United States fell by $5.5 \%$, while across six major OECD countries (Australia, Austria, Canada, West Germany, Sweden and the UK), they rose by $22.6 \%{ }^{3}$ Similar trends of falling real earnings of US workers compared to those in other Western countries prevailed among women. However, in contrast to men, US women experienced absolutely rising, rather than stagnating, real earnings and the other countries did not gain on the United States as rapidly: female wages rose by $15.3 \%$ in the US and $31.6 \%$ in the other countries.

To some degree, these trends in relative real wages may reflect the other Western countries catching up to US levels, a process that started long before 1979. For example, OECD indexes of real compensation per employee rose by $29.2 \%$ from 1970 to 1980 in the six countries just mentioned, compared to a rise of only $8.0 \%$ in the United States. ${ }^{4}$ While, as noted, this convergence continued into the late 1990s, US median real (purchasing power corrected) wages in the 1994-98 period were still 12\% higher for men and 14\% higher for women than in these six other OECD countries. Thus, some further catch up may still occur. Moreover, regardless of the reasons for these trends, the slower growth of real wages in the US over at least the last 30 years may or may not be a cause of its falling relative unemployment rate. Below, we seek to shed some light on this question.

At the same time that the real wages of the median worker in the United States deteriorated relative to other Western nations, Americans at the bottom fared even worse. US men at the $10^{\text {th }}$ percentile experienced a $16.3 \%$ decline in their real wages between $1979-81$ and 1994-98, while workers at the $10^{\text {th }}$ percentile in the six OECD countries listed above saw an increase of $18.8 \%$. Among women, real wages of workers at the $10^{\text {th }}$ percentile fell by $2.8 \%$ in

\footnotetext{
${ }^{3}$ We take these earnings data from an OECD electronic dataset, portions of which are published in OECD 1996. The authors are grateful to Jonas Pontusson for his help in obtaining that file. All figures are expressed in 1998 US dollars using the Personal Consumption Expenditures deflator; foreign earnings figures are purchasing powercorrected using OECD (1998b).

${ }^{4}$ Data are from the OECD Statistical Compendium CD-Rom, deflated by own country prices.
} 
the United States, compared to an increase of $28.8 \%$ in the other countries. Moreover, by the 1994-98 period, workers at the $10^{\text {th }}$ percentile in these other countries had surpassed Americans in real earnings levels, with men having a $21 \%$ advantage and women a $9 \%$ advantage over their US counterparts. At the bottom of the wage distribution, the United States has some catching up of its own to do. ${ }^{5}$

Thus, while the US economy may have been an impressive job-creation machine since the 1970s, real wages in the United States have risen more slowly than those in other countries, and workers at the bottom have fared particularly poorly. If unemployment is Europe's signature problem at the turn of the century, low and declining real and relative wages for those at the bottom of the wage hierarchy are America's.

This paper seeks to shed light on the unemployment experience of the United States in an international context. We analyze the dynamics of aggregate unemployment, building on the framework proposed by Blanchard (1999) and Blanchard and Wolfers (2000). In addition, we track international differences in the composition of employment and wage outcomes across demographic groups. These disaggregated outcomes are of interest in their own right, and evidence on them can also help us understand the fundamental causes of differing aggregate unemployment outcomes. We aim at characterizing possible labor market configurations with respect to a variety of performance indicators on the one hand, and their relationship to various institutional features of the labor markets of industrialized countries on the other.

Section 2 discusses the basic theoretical approach we adopt towards understanding international differences in unemployment. Like Blanchard and Wolfers (2000) and other recent contributions, we argue that institutions and economic shocks interact to produce differing outcomes. This framework offers a "Unified Theory" of labor market outcomes (Blank 1997) and suggests that the same macroeconomic forces will produce differing unemployment and wage outcomes depending on a country's institutional makeup.

\footnotetext{
${ }^{5}$ In 1979-81, these positions were reversed with US men at the $10^{\text {th }}$ percentile outearning their foreign counterparts by $18 \%$ and US women at the $10^{\text {th }}$ percentile having a $21 \%$ wage advantage.
} 
Section 3 offers a preliminary descriptive analysis of long-run labor market developments across a broad panel of industrialized countries. We initially focus on two headline indicators of labor market performance, aggregate unemployment and overall wage inequality. The dynamics of these two variables have been sources of concern in the past twenty years - the latter increasing in the US and other Anglo-Saxon countries, the former increasing in Continental European and other heavily regulated countries. We find that country and period fixed effects account for a large proportion of labor market performance variation. However, the available data do appear to outline a tradeoff between wage inequality and unemployment, albeit one that is far from being stable over time and across countries. ${ }^{6}$ We also find evidence of a weaker tradeoff between unemployment and real wage levels.

We proceed to analyze the role in policy tradeoffs of country-specific macro shocks (Section 4) and microeconomic structural features such as the demographic composition of the population (Section 5). Section 6 reviews theoretical perspectives on the relevance of institutions (such as the extent and character of collective bargaining arrangements and employment protection systems), and assesses their empirical explanatory power in our data set. In this section, we also discuss recent changes in labor market institutions in the OECD countries and estimate the effects of these changes on unemployment in the US vs. other countries. In Section 7 we discuss the demographic composition and character of employment and unemployment.

Our empirical specifications allow macro shocks and microeconomic structural factors to interact with country-specific institutional features to affect aggregate and disaggregated labor market performance indicators. We use our econometric estimates to explicitly account for USother country differences in employment outcomes. For each empirical specification, we apply the parameter estimates to US-other country differences in institutional, demographic, and

\footnotetext{
${ }^{6}$ There is a large literature investigating the degree to which wage inequality is associated with relative unemployment or employment of particular skill groups. Some studies find that in countries where a specific group, eg youth, have high relative wages, its members have low relative employment, while other studies do not find evidence of such a relationship between relative wages and relative employment. For a review, see Blau and Kahn (1999).
} 
macro-shock variables. This comparative approach brings information beyond US time trends to bear on understanding the sources of US success in achieving low unemployment. It also makes it possible to simulate what would have happened to the US unemployment rate under different labor market institutions given the macro shocks experienced. Section 8 updates our empirical analysis to check its robustness and explore its implications for current US developments. Section 9 concludes.

\section{Labor Market Institutions and Outcomes: A Unified Theory?}

The United States labor market has long been much less subject to collective intervention by unions or government than that of other Western countries. It is commonly argued that these differences are key to understanding the differences in unemployment, wage levels, and wage inequality discussed above (e.g. Siebert 1997). While some controversy surrounds the effort to link the institutional differences to labor market outcomes, the broad outlines of these disparities are clear.

First, collective bargaining plays a much smaller role in determining workers' wages in the United States, with its low rate of collective bargaining coverage and predominantly singlefirm bargaining units in the union sector, than in many of these other countries, particularly those in central and northern Europe, where wage agreements are made at the industry or even the economy level. And legislated minimum wage levels are also higher relative to average wages in these other countries than they are in the United States (OECD 1998a). There is abundant evidence that these more interventionist labor market institutions that are prevalent in the other OECD countries lead to compressed wage differentials along several dimensions such as industry, age and gender. However, the evidence that this wage compression generates employment problems for those with high relative wages is mixed (Blau and Kahn 1999). Second, unemployment insurance (UI) benefits are much more generous in other OECD countries than in the United States, and while UI benefits usually run out after 6 months in the United States, unemployed workers can collect for much longer periods in other countries. 
Third, it is much more expensive and administratively cumbersome for firms in other OECD countries to lay off workers or employ temporary workers than it is in the United States (OECD 1999). Moreover, the government is typically a much more important employer in other OECD countries than in the United States. While the public sector share of employment has been falling steadily in the United States since the 1970s, largely as the result of strong private employment growth, the opposite is true in most other OECD countries (Gregory and Borland 1999, p. 3575). Finally, mandated benefits such as parental leave and sick leave are much more generous in these other countries than they are in the US (Nickell and Layard 1999).

As noted above, some have pointed to several of these major differences in the degree of intervention in the labor market as important causes of the relatively high unemployment in other Western nations compared to the United States, although it should be acknowledged that some of these differences (e.g., the high incidence of government employment or the generosity of unemployment benefits) may be in part a response to high unemployment in these other countries. On its face, one difficulty with such an argument is that, in the 1960s and early 1970s, with largely the same differences in labor market institutions between the United States and other Western nations, it was the United States that was the high unemployment country. Thus it cannot be true that interventionist institutions produce high unemployment all the time. However, consideration of the vast differences between the United States and other Western countries in wage setting and other labor market institutions has suggested a plausible interpretation of the relationship between these institutions and the unemployment disparities that have prevailed since the early 1970s. This view essentially posits an interaction between labor market institutions and labor market shocks.

This interaction can be understood by first noting that since the early 1970s, there have been a variety of shocks to which labor markets in all countries have been exposed, including the slowdown in productivity growth dating from the early 1970s, the oil price increases of the 1970s and early 1980s, the fall in the relative demand for unskilled labor since 1980, and disinflation in the 1980s and 1990s (Layard, Nickell and Jackman 1991; Freeman and Katz 1995; 
Blanchard and Wolfers 2000; Ball 1997 and 1999). It has been hypothesized that the flexible US labor market was able to accommodate these shocks by letting absolute and relative real wage levels adjust, allowing its unemployment rate to stay low. In contrast, in most other OECD countries, labor market institutions kept overall real wages rising and prevented unskilled workers' relative wages from falling as fast as they did in the less restricted US market (in some cases preventing any fall in low skilled workers' relative pay), thus producing sharp increases in unemployment in these countries (Blanchard and Wolfers 2000; Freeman 1994). As discussed further below, some of these macroeconomic factors, particularly disinflation policies or shifts in the demand for unskilled workers, can be affected by institutions or by unemployment itself. However, the logic of the argument is still compelling: keeping wages rigid in the face of shifting supplies and demands is likely to have effects on employment.

From the perspective of such a "Unified Theory" (Blank 1997), Europe's experience of rising unemployment, rising real wages, and comparatively stable relative wage levels is the other side of the coin to the US experience of falling unemployment, falling to steady real wages, and rapidly rising wage inequality. Up to the early 1970s, the relatively low unemployment rates of European countries may have reflected slow catch-up of real wages in the presence of relatively fast productivity growth, or the small relevance of frictional unemployment noted above. Thereafter, the US allowed real and relative wages to adjust, while in Europe and other Western nations employment took the brunt of the shocks.

To illustrate the basic argument, consider the impact of productivity trends. From the 1960s to the 1990s, annual growth in total factor productivity in the OECD fell from 5-6\% to 12\% (Blanchard and Wolfers 2000). Total factor productivity growth is the growth in output per worker beyond that which can be explained by changes in the amounts of labor and capital used. It is thus a measure of technological progress. In the relatively flexible US labor market, real wages were allowed to grow more slowly and even to decline, thus mitigating the adverse effect 
of the productivity decline on unemployment. ${ }^{7}$ As shown by Ball and Moffitt (2001), even in the US, real wages adjust with a lag to changes in productivity growth. But in many other OECD nations, unions and other labor market institutions kept real wages growing at their customary pace instead; this led to higher unemployment. In Ball and Moffitt's terms, this argument suggests that wages in these other countries adjusted to productivity with considerably longer lags than in the US. Conversely, when productivity growth is unusually rapid, real wages may adjust more quickly in flexible labor markets like the US's than in rigid labor markets, implying that employment should actually grow by more in the countries with interventionist institutions. This kind of interaction may indeed play a role in explaining the low unemployment observed in the 1960s in much of Europe. It could also, at least in principle, be relevant to US labor market dynamics in the aftermath of the recent high labor productivity growth documented and analyzed by Oliner and Sichel (2000).

In addition to explaining why a flexible labor market should be better able to generate higher aggregate employment rates under certain conditions, the Unified Theory has implications for disaggregated employment indicators: to the extent that high wage floors prevent low-wage employment opportunities, employment problems in the interventionist countries should be especially severe for individuals who would command relatively low wage rates in laissez faire labor markets. Available evidence on these employment problems is mixed, with some studies finding that intervention does reduce the relative employment of the less-skilled, while other studies do not find this result (Blau and Kahn 1999). This question is difficult to answer conclusively because wage and employment opportunities depend on demographic and other less readily observable worker characteristics as well as on measured skills, and earnings inequality also reflects heterogeneity across jobs when worker mobility is not perfect (Bertola and Ichino

\footnotetext{
7 The theory sketched here views employment as demand-determined. Thus, anything that restrains real wage growth raises employment. In other models of employment determination at the micro level, including efficient bargaining or employer monopsony models, wage increases may instead be positively associated with employment changes. For further discussion, see Farber (1986) or Card and Krueger (1995).
} 
1995). We next examine available data from the theory's perspective, and proceed to evaluate its aggregate and compositional predictive power.

\section{What is to Be Explained?}

To analyze recent trends in labor market outcomes across countries, we have assembled a crosscountry time-series data set building on that constructed and analyzed by Blanchard and Wolfers (2000). We draw variables pertaining to unemployment, macro shocks, and labor market institutions from the Blanchard-Wolfers dataset. We have added data on wage distributions, labor force by age groups, population by age groups, and unemployment rates by age groups for male and female workers separately. We have also included additional labor market institutions indicators. (See the Data Appendix for additional details.) The countries included are Australia, Austria, Belgium, Canada, Denmark, Finland, France, Germany, Ireland, Italy, Japan,

Netherlands, New Zealand, Norway, Portugal, Spain, Sweden, Switzerland, the UK, and the US. Along the time dimension, observations are arranged in 5-year intervals from 1960-64 to 199094, so as to smooth out short-term fluctuations. The final observation of the Blanchard-Wolfers dataset refers to 1995-96 time-averaged data. To preserve comparability with those authors' results, the dataset analyzed in this and the next few section also uses only 1995-96 information in constructing the "1995" period average. In the last section of the paper, we present some updated information for the 1995-99 period for a limited sample of countries, and discuss how the proposed long-run, cross-country perspective may illuminate the recent striking developments in the US labor market.

To begin with, we review time-series and cross-country variation in a few key variables of interest. Table 1 contains data on unemployment rates for the subset of countries for which data are available for both 1970-4 and 1995-6 in the Blanchard and Wolfers data set. The Table shows that unemployment is highly variable along both time series and cross sectional dimensions, ranging from less than $1 \%$ for New Zealand in the $1970-74$ period, to $23 \%$ in 1995 96 for Spain. From the perspective of this paper, it is of course most interesting to focus on the 
US unemployment rate vis-à-vis that of other industrialized countries. For the purpose of such comparisons, throughout the paper we contrast the US unemployment rate with the unweighted average of unemployment rates in the non-US countries represented in the sample.

In 1970-4, unemployment averaged $2.54 \%$ in the non-US countries of the BlanchardWolfers sample, while it was $5.41 \%$ in the US. By 1995, the non-US countries had experienced a well-publicized increase in unemployment to $10.66 \%$, while the US rate was $5.55 \%$, roughly its 1970 level. It is this reversal of unemployment fortunes that we are most interested in documenting and interpreting, focusing in particular on its association with other labor market performance indicators. (Of course, the US unemployment rate eventually came down to a September 2000 level of $3.9 \%$. In the concluding section of the paper, we discuss how our longrun, cross-country empirical perspective may shed light on such recent developments). ${ }^{8}$

Our data include comparable wage distribution statistics for a subset of countries and periods. Unsurprisingly, heterogeneous levels and dynamics are observable in the US and other countries as regards such indicators. First, Table 2 shows log median real wages (using the Personal Consumption Expenditures deflator) in purchasing power parity (PPP)-corrected 1998 US\$ for full-time male workers. We focus on male wages as an indicator of wage trends, since men are a more homogeneous group than women, although our data base and other work have shown similar trends for female wages and wage inequality in the US and other countries (Blau and Kahn 2000a). Median real wages have grown more slowly in the US than in the other OECD countries shown in Table 2. For example, between 1975-9 and 1995-6, US real wages fell by $4 \%$, while they rose by $23 \%$ in the other six countries for which data were available (Australia, Finland, France, Japan, Sweden and the UK) ${ }^{9}$, although as discussed earlier, real wages were still higher in the US in the 1990s than elsewhere, suggesting room for further convergence.

\footnotetext{
8 The unemployment rates discussed here are not standardized. However, in a later section we analyze a subset of countries and periods for which OECD-standardized data are available and reach largely the same conclusions.

9 These statements about percentages are approximations, since the data are expressed in logs.
} 
Table 3 shows data on wage inequality (measured by the 50-10 percentile log difference over the distribution of wages). We focus on the 50-10 wage gap in view of the importance of wage floors in economies with extensive collective bargaining coverage and centralized wagesetting institutions in which these floors are negotiated (Blau and Kahn 1999). The data are rather sparse, especially in the early periods. Their message, however, is similar regardless of whether the US-other countries unweighted average comparison is done on all available data in each year, or only on the subset of countries for which wage information is already available in 1975-79 (i.e., Australia, Finland, France, Japan, Sweden, and U.K.). The data indicate that wage inequality has always been higher in the US than in other industrialized countries, and has increased more rapidly there as well.

How are wage and unemployment performance related to each other? Raw data are not revealing: univariate regression coefficients of unemployment on wage levels or on wage inequality are insignificant. Patterns are much more readily apparent, however, if the variability of key labor market indicators is decomposed into its country-specific, period-specific, and residual components. To pursue this decomposition, we first regress unemployment rates, wage levels, and wage inequality indicators on country and period dummies:

$$
\mathrm{y}_{\mathrm{it}}=\mathrm{a}_{\mathrm{i}}+\mathrm{b}_{\mathrm{t}}+\mathrm{c}_{\mathrm{it}}
$$

where for country $\mathrm{i}$ and period $\mathrm{t}, \mathrm{y}$ is one of the three outcomes (unemployment rate, wage level, or wage inequality), a is a country fixed effect, $\mathrm{b}$ is a common period effect, and c is a countryperiod residual. To understand the meaning of the residual $\mathrm{c}_{\mathrm{it}}$, consider the unemployment rate version of (1) and the US observation for 1990-94. From estimating equation (1), we find that the US country effect is $4.97 \%$, while the $1990-94$ period effect is $3.23 \%$. This implies that the expected US unemployment rate in 1990-94 assuming normal US behavior in the world economy of 1990-94 would have been $8.20 \%(4.97+3.23)$. The actual US unemployment rate in 
1990-94 was $6.58 \%$, implying a residual of $-1.62 \%$; in other words, unemployment in the US was unexpectedly low in 1990-94.

Having estimated equation (1) for unemployment, wage levels, and wage inequality, we next analyze statistically and graphically relationships between the residuals and the role of timeeffects. This procedure allows us to remain agnostic as to the direction of causality between labor market performance indicators, and offers useful insights into possible structural relationships among them.

In pairwise regressions of unemployment residuals on wage level residuals or wage inequality residuals, the coefficients are significant, subject to some interesting qualifications. After controlling for country and time effects, a positive wage level-unemployment residual relationship is apparent in Figure 1. One interpretation of this relationship is that the period effects remove the impact of common increases in productivity from wage level determination. If a country's real wage is especially high relative to this trend and to its normal real wage level, then unemployment is also on average unexpectedly high. The statistical significance of the unemployment residual-wage level residual relationship, however, is largely driven by USspecific time-series developments, possibly reflecting the role played by convergence phenomena in shaping US relative average wage dynamics. When the US is in the sample, the partial correlation coefficient is is 0.305 ; but it is only 0.087 when the US is excluded, and its statistical significance drops to $15 \%$ if the panel structure of the residuals is taken into account when computing the variance-covariance matrix.

The relationship between unemployment and wage inequality (as measured by the 50-10 $\log$ wage differential, and illustrated in Figure 2 after controlling for country and period effects) is very strong and much more robust. When unemployment residuals are regressed on wage inequality residuals (to yield the regression line plotted in the figure), and also when the reverse regression is run, the statistical significance of the negative slope coefficient is robust to the exclusion of US observations and to correction for residual variance clustering. The slope of the unemployment-wage inequality tradeoff is significant not only from the statistical, but also from 
the economic point of view. Controlling for country and period effects, the coefficient on the 50$10 \log$ wage differential in a regression where unemployment is the dependent variable is -0.241 , with a t-statistic of -4.68 (the coefficient on unemployment in the reverse regression is -0.944 , with a t-statistic of -4.07). The inequality-unemployment tradeoff illustrated by such regressions would indicate that an increase of 0.1 in the wage inequality measure "buys" up to 2.41 percentage points of unemployment. To put this tradeoff in perspective, consider that between 1970 and 1995 US wage inequality as measured by $\log 50-10$ wage differentials increased by 0.18 , and French inequality decreased by 0.11 . If these movements had happened along a stable tradeoff, relative wage inequality developments should have been associated with a divergence of 6.96 percentage points in the unemployment rates of the two countries. As Table 1 shows, French unemployment rose by 8.83 percentage points, while the US rate rose by only 0.09 percentage points. Thus, the tradeoff illustrated in Figure 2 accounts for almost $80 \%$ of the diverging unemployment patterns for these two countries over this period.

Importantly, a tradeoff between unemployment and wage inequality is only apparent after removing country and period effects. We do not report country effects, which presumably reflect institutions as well as the demographic- on which more below - and structural features of each economy. Spain's large fixed unemployment effect over the period, for example, may well be a reflection of its labor force's transition out of the agricultural sector, a convergence phenomenon. Treating such features as time invariant is only an approximation, of course. To the extent that unemployment and wage inequality both depend endogenously on a host of country- and timedependent variables, the evolution of unemployment and wage inequality should be explained in terms of the evolution over time of each country's specific characteristics, some of which we will be able to include in more structural empirical specifications below.

The scope of empirical exercises is, however, obviously constrained by the fact that potentially relevant country specific characteristics are not always observable, and certainly more numerous than the countries on which we have information. Accordingly, the proposed organization of information in terms of fixed and period effects does offer a useful summary 
perspective on labor market developments. Most interestingly, we find that period effects increase over time in both the unemployment and wage inequality regressions whose residuals are plotted in Figure 2. If we treat unemployment as the dependent variable, and regress deviations from country means for unemployment on wage inequality deviations from country means and period dummies, we find that the coefficients of the latter increase significantly over time. For example, this period effect is found to be 1.47 percentage points higher in 1975-80 than in 1970-75; to increase further (by $1.49,0.23$, and 1.17 percentage points) in the following five-year periods; and to be 0.78 points higher in 1995-96 than in 1990-94. This means that, within countries, the unemployment-wage inequality relationship is getting worse over time.

In summary, the evidence does point to a tradeoff between unemployment and wage inequality, but indicates that the tradeoff-not unlike an expectations-adjusted Phillips curve-is not stable. Its slope is negative and statistically constant over time: only the 1995-96 periodinequality interaction is significant ( $\mathrm{p}$-value $=0.07$ ), while allowing all other slopes to change over time receives no statistical support ( $\mathrm{p}$-value $=0.67$ ). The tradeoff's intercept, however, is different across countries and appears to deteriorate steadily over time, moving to higher unemployment for a given level of wage inequality.

This evidence is descriptive rather than causal, of course, but structural mechanisms may easily imply a negative association between wage inequality and unemployment across different institutional arrangements. As we discuss in Section 6 below, collective bargaining and other labor market institutions tend to reduce wage inequality, effectively truncating the underlying distribution of wages across different individuals and jobs and eliminating employment opportunities for low-wage workers. This will contribute to overall unemployment, and affect the observed levels of median wages and wage inequality.

While structural interpretations are plausible, it must be acknowledged that if unemployment primarily affects those at the bottom of the skill distribution, there will be a mechanical positive relationship between unemployment and the observed wage median. Moreover, if the wage distribution realistically has more mass near the median than at the $10^{\text {th }}$ 
percentile, then truncation from below will also narrow the observed 50-10 gap, producing a negative relationship between unemployment and observed wage inequality. Since anything else that raises unemployment will very likely also affect the observed wage distribution, the discussion of truncation raises the possibility that the causality runs from unemployment to median wages and wage inequality rather than the reverse. However, Blau and Kahn (1996 and 2000a) control for this truncation and still find higher levels of wage inequality in the US than in other countries. Their evidence suggests that laissez faire labor market institutions, supply of literacy skills, and population heterogeneity could play important roles in shaping the extent of wage inequality. Of course, the shape of wage distributions across observed employment relationships is likely not independent of the fact that their low-wage portion is truncated. For example, workers may be induced to upgrade their skills when they do not succeed in obtaining a job, especially if education and training are subsidized. Thus, labor market institutions may affect wage inequality indirectly through their impact on the supply of skills.

\section{The Role of Macroeconomic Shocks}

In this and the following two sections we examine possible explanations for the reversal of unemployment fortunes characterizing the US and the other OECD countries. Can we understand why the US went from being a high unemployment to a low unemployment country between the 1970s and the 1990s? An obvious candidate for explaining such a reversal is that macroeconomic shocks may have been less favorable for the US than other countries in the 1970s but more favorable in the 1990s. To investigate this possibility, we turn to Blanchard and Wolfers' (2000) data and use their analysis as a base from which to proceed. Blanchard and Wolfers summarize the macroeconomic shocks affecting each country by measures of:

i) Changes in productivity growth, measured on a total factor productivity (tfp) basis as the growth in output per work hour after controlling for changes in the quantities of other factor inputs. This measure of technological progress has substantially slowed across the OECD since the 1960s. Reduced tfp growth can result in higher unemployment for 
several years if labor market institutions keep real wages rising at their customary pace. ${ }^{10}$ In the long run, there is no reason for unemployment to be affected by the particular level of tfp growth a country has settled upon, but it may take a long time for real wage growth to decelerate to its new equilibrium level. Thus, higher unemployment in the face of slower tfp growth can persist over the 5-year periods used in the analysis.

ii) Changes in the ex post real interest rate, a summary measure of the cost of capital, which fell across the OECD from 1965 to 1975 but then rose steadily. Higher real interest rates restrain economic activity and therefore contribute to higher unemployment. As was the case for the productivity growth slowdown, rising real interest rates are expected to cause larger increases in unemployment the more rigid are real wages. The fact that real interest rates were higher overall in the 1990s than they were in the $1960 \mathrm{~s}$ and 1970s can therefore help to explain the rise in OECD unemployment rates.

iii) Shifts in labor demand over time, measured in terms of changes in labor's share of total business-sector income. By this measure, labor demand shifted upward in Europe between 1960 and 1975 but fell steadily through the 1990s to well below its 1960 level. Labor's share fell steadily in the US over the same period. As Blanchard and Wolfers note, this reduction in labor's share could have been due to downsizing and leaner production methods. The lower level of labor demand can be associated with lower employment if, again, real wages fail to adjust to it.

iv) Changes in inflation which, to the extent that they are not fully anticipated and nominal wages are pre-set, can cause deviations of observed unemployment from its equilibrium level. ${ }^{11}$ Across the OECD, inflation was increasing in the $1970 \mathrm{~s}$, but has been decreasing

\footnotetext{
${ }^{10}$ While one might also consider the oil shocks as worthy of inclusion, their impact may be subsumed by the change in tfp. Moreover, Blanchard and Wolfers (2000) show that the magnitude of the impact of the tfp slowdown on labor markets dwarfs that of the oil shocks.

${ }^{11}$ This equilibrium unemployment rate is best thought of as a kind of medium-term equilibrium that corresponds to a particular set of macroeconomic shocks and a constant inflation rate (Blanchard 1997; Blanchard and Wolfers 2000). How long it takes the economy to adjust to changes in total factor productivity growth, real interest rates and labor demand shifts (the major shocks considered here) is an empirical question. In Section 6.5 we consider the possibility that disinflation can have more permanent effects on unemployment, as argued by Ball $(1997,1999)$.
} 
in the 1980s and 1990s, so unemployment may have been below its equilibrium level in the 1970s and above it in the 1980s and 1990s, at least on average.

Table 4 shows mean values for unemployment, these four shocks, and time invariant measures of institutions (discussed below) in 1970-4 and 1995-6. Data are displayed for the United States and for the unweighted average of other countries for which data are available for both periods: Australia, Belgium, Canada, Finland, France, Italy, Japan, Netherlands, New Zealand, Spain, Sweden and the UK. Each variable is signed so that an increase is expected to raise unemployment. Thus, labor demand, tfp growth and the change in inflation have all been multiplied by minus one. Table 4 indicates that the unemployment rate rose in the non-US countries relative to the US by 8.04 percentage points over this period; and it is this change that we wish to explain.

The data in Table 4 indicate that the labor demand variable, which as explained by Blanchard and Wolfers (2000) in their data appendix is based on the log of labor's share of income, shows an increase for the both the US and the non-US countries over the 1970-95 period. This means that labor's share fell. The last column of Table 1 shows that labor's share actually fell by more in the United States than elsewhere, and thus should have contributed to a rising US unemployment rate relative to the other countries. This means that in order to explain the reversal of relative unemployment rates between the US and the other countries, other factors other must outweigh the effects of labor demand.

Real interest rates rose both in the US and in the other countries, with a larger rise in the other countries. The difference in real interest rate behavior is thus a contender for explaining the US-other country unemployment divergence. Total Factor Productivity (tfp) growth variable is less negative in 1995 than in 1970 for both the US and the other countries. This means that tfp growth slowed, and the last column of Table 1 shows that it decreased more outside the US. This then is another factor that could help to explain the divergence in unemployment experience between the US and other countries. 
Finally, the change in inflation is also signed in the perverse way. The negative signs in 1970 mean that inflation increased over the $1970-74$ period. The inflation figures for 1995 are positive, implying that inflation decreased during 1995 and 1996. The last column of Table 1 shows that inflation decreased by more in the other OECD countries than in the US, a further potential contributor to the rising unemployment rates in the non-US countries. ${ }^{12}$

We now examine the extent to which the shock measures proposed and exhaustively discussed by Blanchard and Wolfers can explain the declining unemployment rate in the US relative to the other OECD countries. We first present and discuss our regression results and then use the parameters to see how much of US-other country differences the regression models can explain. We augment Blanchard and Wolfers' (2000) models by adding the change in inflation as an explanatory variable, by controlling for period effects in some of our models, by examining the extent of autocorrelation, and by controlling for demographic developments (Section 5). These modifications are discussed in the context of our consideration of the results of estimating the models.

The first two columns of Table 5 show ordinary least squares (OLS) unemployment rate results for the Blanchard and Wolfers (2000) sample where we include only macroeconomic shocks and country dummies as explanatory variables. ${ }^{13}$ Rather than computing equilibrium unemployment rates by making a priori assumptions about the impact of inflation changes on unemployment, as in Blanchard and Wolfers (2000), we have simply included the change in the inflation rate as a regressor determining the actual unemployment rate. This allows the data to resolve the essentially empirical question of the extent to which unemployment can deviate from its medium-run equilibrium level over the five year periods considered. It also gives macro shocks their best shot at explaining the evolution of relative unemployment rates over time

\footnotetext{
${ }^{12}$ Ball (1997 and 1999) emphasizes disinflation as a key factor explaining the rise in natural unemployment rates in Europe. Below, we evaluate his models to see how well they explain US-other country differences in the natural unemployment rate.

${ }^{13}$ In addition, in all of our models, we include a pre-Portuguese revolution dummy variable (a variable that equals 1 for Portugal before 1975 and 0 otherwise) in light of Blanchard and Wolfers' (2000) arguments that such a control is warranted. Our basic results were not affected by excluding this variable.
} 
before we appeal to institutions as an additional explanatory factor. We shall see in Section 6 that the impact of the change in inflation on unemployment is empirically much smaller in the US than elsewhere, suggesting a more flexible nominal wage response to changing inflation. Our decomposition results, however, were not substantially different in specifications where equilibrium unemployment was imputed as in Blanchard and Wolfers (2000).

The first model in Table 5 shows that each of the shocks is associated with unemployment in the expected direction. We must be aware, however, that each of these macro variables can themselves be affected by unemployment. For example, one would expect the government to attempt to lower real interest rates in response to high unemployment. Or, to take another example, higher unemployment is likely to lead to declining inflation, as demand falls. Such reasoning thus implies a simultaneous equations bias on policy-affected macro variables, such as real interest rates or disinflation, which makes it harder than otherwise to find the expected effect of these variables on unemployment. Moreover, while labor's share may be influenced by downsizing, as argued by Blanchard and Wolfers (2000), it also can be influenced by the technical elasticity of substitution between labor and capital. Thus, the long term decline in labor's share shown in Table 4 may not reflect shifts in the demand for labor. Finally, it may be artificial to assume that each country is affected only by its own macroeconomic shocks. We are all part of a world economy, and there may be many common effects across countries.

Lacking suitable instruments for macro policy, we must acknowledge that our estimates for these variables may be biased downward in absolute value. And the previous comments about labor's share and common shocks across countries suggest that these variables may at best measure macroeconomic effects with errors. However, the ordinary least squares (OLS) model does yield the credible results that less labor demand, higher real interest rates, slower growth in total factor productivity, and disinflation are all associated with relatively high unemployment across countries and over time. examination of the residuals shows a significantly positive autocorrelation coefficient of .317 . The presence of autocorrelation does not bias the coefficient estimates; but the estimated standard errors are potentially biased. Since we are primarily 
interested in whether the coefficients can explain the US-other country unemployment gap over time and since we would lose 20 of 131 observations in correcting for autocorrelation, we use the OLS coefficients. Table 5 shows that, using this model, changes in macro shocks predict a rise of $3.58 \%$ in US unemployment compared to an increase of $5.64 \%$ in the other countries. Macro shocks have evidently been more favorable in the US. However, based on these estimates, they can explain only $26 \%$ of the divergence in relative unemployment rates.

The second model in Table 5 adds period dummies, which were not included in Blanchard and Wolfers' specification. This accounts for the possibility mentioned earlier that world-wide events, such as oil crises, affected all countries similarly. The advantage of including period effects rather than measures of specific world-wide factors such as changing oil prices is that period effects pick up the net impact of all of these events. Of course, such events should in principle work through the shock variables. To the extent that the significant period effects we typically find (even when, in results not shown here, we take account of autocorrelation) absorb the common disinflation or real interest rate trends across OECD countries, the model including period effects understates the full impact of these macro shocks. ${ }^{14}$ Conversely, if unemployment is partly driven by omitted worldwide forces that are positively correlated with the included macro shock measures, then the models without period effects overstate the impact of macro shocks. While we cannot be certain of the underlying explanation, we note that when we add period effects the coefficient of total factor productivity becomes perversely signed, and the coefficients for the real interest rate and the change in inflation become much smaller (the labor demand coefficient rises moderately). After accounting for period effects, macro shocks explain none of the US-other country divergence in unemployment (accounting for $-0.6 \%$ of the change).

Based on the results obtained in these two OLS specifications, we conclude that macroeconomic shocks by themselves can explain at most $26 \%$ of the reversal of unemployment

\footnotetext{
${ }^{14}$ We note that the macro shocks are highly correlated with period effects. For example, when we regressed each shock on country dummies and period dummies, the latter were significant as a group in each case at better than .0001 level.
} 
fortunes of the US compared to the other OECD countries. The possible simultaneous equations and measurement error biases discussed above imply that the estimated effects of the macroeconomic shocks in these simulations using the estimated coefficients may be biased downward. However, these estimates suggest that it would be fruitful to consider other possible explanatory variables, which we do in the following sections.

\section{Demographic Developments}

One of the ways in which we extend the analysis of Blanchard and Wolfers (2000), in addition to focusing explicitly on US-other country comparisons, is to bring in demographic changes as a factor that may help to explain the international unemployment patterns. In particular, we focus on the youth share of the population (i.e. the number of people between the ages of 15 and 24 as a fraction of the number of people 15 years old and over) as a potentially important factor influencing the overall unemployment rate. We use youth population share rather than youth labor force share, since labor force decisions are directly affected by unemployment (youth population share is also potentially so affected, and we deal with this possibility below). While institutions such as schooling policies can affect the pressure a given youth population puts on the labor market, the inclusion of country dummies may control for these. There are several, possibly opposing, routes through which the youth share can affect the overall unemployment rate.

First, in an accounting sense, a larger youth share can raise unemployment since youth are a high unemployment group. Katz and Krueger (1999) have attributed a portion of the decrease in the US unemployment rate in the 1990s to a falling youth share of the population. Second, in contrast to this accounting mechanism, Shimer (1999) argues that a greater youth share may actually lower unemployment by reducing employer search costs. In this framework, business formation and business expansion depend on employers' ability to find workers willing to relocate. A larger youth share of the population implies a larger share of such mobile workers and may thus contribute to higher employment for both youth and complementary adults. 
Shimer (1999) finds evidence in favor of this hypothesis within the US: states with larger increases in youth share in the population had larger reductions in unemployment, even taking into account the endogeneity of youth share (more on this below). However, across countries, there was no effect of youth share on unemployment. Shimer suggests that the different withinUS and cross-country findings reflect the far greater mobility of capital across states in the US than across countries in the OECD. Korenman and Neumark (2000), however, do find crosscountry evidence that a higher youth share is associated with higher relative unemployment of young people, suggesting imperfect labor market substitution effects on the demand side.

As we noted above, the youth share may be endogenous with respect to unemployment. Specifically, we expect young people, who tend to be more mobile than older people, to be attracted to expanding labor markets. There may thus be a spurious negative correlation between youth share and unemployment. To take account of this possibility, both Shimer (1999) and Korenman and Neumark (2000), in their analyses of the impact of youth share on overall unemployment and youth unemployment, use as an instrument for youth share the incidence of births 15-24 years ago. This variable is clearly expected to affect the current youth share, and is only related to current economic activity if the latter is serially correlated with at least a 15 year lag. Thus, to address the endogeneity problem, in some of our specifications we replace youth share with (births 15-24 years ago/population 15-24 years ago), in effect running reduced form models. $^{15}$

We were able to obtain youth share and prior births data for a subset of the original Blanchard-Wolfers data base, as shown in Table $6 .{ }^{16}$ We lost 28 of the original 131 observations, and Table 6 shows mean values for key variables among the common countries that had 1970-74 and 1995-96 data for all variables. In addition to the United States, these

\footnotetext{
${ }^{15} \mathrm{We}$ also tried instrumental variables (IV) models with similar results. However, the IV version of the nonlinear least squares models we use to analyze institution-shock interactions in Section 6 failed to converge. We did, however, obtain convergence when we replaced youth share with the lagged birth rate variable.

${ }^{16}$ Much of the population data came from the ILO, and in many cases were available only in 10 year intervals. We interpolated where possible to produce 5 year intervals that matched the 5 year intervals in Blanchard and Wolfers (2000).
} 
countries include Australia, Canada, Finland, France, Italy, Spain, Sweden, and the UK. Data on Belgium, Netherlands, and New Zealand were not available for at least one of these two periods and hence these countries are dropped. Table 6 shows that unemployment in the subsample of remaining countries behaved similarly to the larger sample shown in Table 4, rising 8.25 percentage points, very similar to the increase of 8.13 percentage points shown in Table 4 . The macro shocks also changed similarly in the subsample as in the larger Blanchard-Wolfers sample.

Results presented in Table 6 indicate that youth share, indexed either by the share of youth in the population or by the incidence of births 15-24 years ago, fell both in the US and elsewhere, reflecting the aging of the baby boom generation. However, the decrease in both measures was larger in the US than in the other countries. Therefore, if a larger youth share raises the unemployment rate, demographic trends are a potential explanation for the relative fall in US unemployment. On the other hand, if Shimer's (1999) model is valid, then a falling share of youth will actually raise unemployment, and these demographic trends would go counter to the observed unemployment trends.

Table 7 shows results from the unemployment model including only macro shocks but estimated on the subsample of 103 country-period observations with demographic information. The results are quite similar to those for the full Blanchard-Wolfers sample shown in Table 5. In particular, macro shocks can explain at most only $10.66 \%$ of the divergence between the US and other countries' unemployment rates over the 1970-74 to 1995-6 period.

Table 8 illustrates what happens when we add youth population share or the more exogenous prior birth incidence to the macroeconomic shocks. The results are qualitatively similar for both variables. When we exclude period effects, the macro shocks all have positive effects and the impact of youth population share and prior births are inconsistent in sign and small in absolute value relative to their standard errors in both cases. When we add period effects, macro shocks again appear less important, but the impact of youth population share and birth incidence, now positive in both cases, become much stronger and are large relative to their 
(albeit uncorrected) standard errors. In our data, unemployment is trending upward, and youth share (or prior births) is trending downward. If, as noted earlier, the period effects represent unmeasured factors affecting unemployment, then these are negatively correlated with youth share and prior births. Excluding period effects in this case will impart a negative bias to the estimated effect of youth share or prior births on unemployment.

The results in Table 8 suggest that differences in demographic trends between the US and the other countries can help to explain their divergent unemployment experiences. Nonetheless, the full set of macro shocks and demographic trends can explain only between $9 \%$ and $26 \%$ of the divergence in unemployment changes. Multiplying the largest estimates for the effect of the demographic variables (i.e., with period effects included) by the US-other country difference in the change in these variables (the last column of Table 6), we can account for $11.4 \%$ (youth share specification) to $23.7 \%$ (prior birth incidence specification) of the diverging unemployment rates. These effects comprise the bulk of the US-other country difference in the change in unemployment rates explained by the regression (13.1\% and $26.3 \%$ respectively) and suggest that differential demographic trends are more important than differential macro shocks, which are partly absorbed by period effects. When period effects are omitted, however, the impact of demographics is very small.

The results presented so far suggest that we have part of the answer to the puzzle of declining unemployment rates in the US compared to the other OECD countries. Macro shocks and demographic developments have been relatively favorable in the US. However, our estimates indicate that these factors can explain only a modest portion of the observed fall in the relative US unemployment rate. This suggests that the full explanation must be more complicated than a simple comparison of macro shocks and demographic trends for the US and the other countries. In the next section we undertake an analysis designed to illuminate this relationship. 


\section{The Role of Institutions}

While macro shocks and other structural features may each have independent effects on employment, wages, and their composition, the "Unified Theory" discussed above suggests that labor market institutions should interact with these shocks to influence unemployment. In this section, we attempt to evaluate the explanatory power of this approach, following and extending Blanchard and Wolfers's (2000) work and focusing on the contrast between the experience of the US and the other OECD countries.

Following Blanchard and Wolfers (2000), we initially consider eight measures of institutional intervention in the labor market originally compiled by Nickell (1997):

i. replacement rate and

ii. duration indicators for the unemployment insurance (UI) system;

iii. a measure of collective bargaining coverage; ${ }^{17}$

iv. a summary indicator of the stringency of employment protection legislation (EPL);

v. an instrumented indicator of expenditure on active labor market policies;

vi. a measure of union density; ${ }^{18}$

vii. a summary indicator of labor taxation, ${ }^{19}$ and

viii. the OECD indicator of wage-bargaining coordination.

Values of these indicators for the US and for the average of other countries are summarized in Table 4 (original Blanchard-Wolfers sample) and Table 6 (youth subsample). Note that these institutional variables are treated as invariant over time. As discussed further below, there has been institutional change along several dimensions, often concentrated in particular countries. The assumption of time-invariant institutions may however be a reasonable

\footnotetext{
${ }^{17}$ In the original Nickell (1997) data base, this variable was essentially defined in three categories. We have defined it as the actual fraction of workers covered by collective bargaining agreements in 1990, a more accurate, continuous measure. This variable was obtained from OECD (1994a).

${ }^{18}$ We include both union density and collective bargaining coverage because it is reasonable to assume that, for a given level of collective bargaining coverage, unions will be stronger the higher the fraction of the workers who are actually union members.

${ }^{19}$ Labor taxation includes income and payroll taxes as well as mandated benefits. It is thus a measure of the wedge between the cost of labor to the employer and the after tax value of working from the employee's point of view (Nickell and Layard 1999).
} 
approximation for the purposes of comparing the extreme case of the United States with other OECD countries, particularly since it has been found that international differences in institutions are much greater than changes over time within countries (Kahn 2000; Blau and Kahn forthcoming). Moreover, Blanchard and Wolfers (2000) obtained stronger findings when they used time-invariant institutional measures than when they attempted to allow for time variation. This may reflect the poor quality of available information on such time variation (see Addison et al., 2000, as regards EPL indicators) and the fact that many forward-looking decisions in the labor market are based on expectations, rather than actual values, of future institutions. Nonetheless, in this section we also report on some results that allow institutions to vary over time, using several data sources that were often incomplete. ${ }^{20}$

\subsection{Institutions and worker protection}

Like the macro and demographic shocks analyzed above, institutional indicators are imperfect measures of the complex real-life phenomena they are meant to summarize. The definition of the institutional characteristics we include in our analysis conforms to those used in earlier analyses of similar issues, and does not need to be discussed in detail. Before proceeding to empirical analysis, however, it is useful to discuss briefly possible rationales for collective institutional interference with the workings of the labor market and, in particular, the role of the specific institutions we consider in the context of the simple theoretical framework outlined in Section 2 above.

Most of the labor market institutions listed above (unemployment insurance, collective bargaining, and unionization indicators) play a straightforward role in limiting wage competition and eliminating low-wage employment relationships. From a static perspective, their association with high wage and low employment labor market configurations follows straightforwardly from the simple reasoning in Section 2 above. To understand the rationale of such institutional configurations and clarify the role of employment-protection provisions, however, it is helpful to

${ }^{20}$ Our results were unchanged when we included a "Thatcher revolution" dummy variable. 
adopt a dynamic perspective. When labor market outcomes are not only different for different individuals at a point in time, but also variable for a given individual over time, then labor market institutions can be seen as providing income insurance - insurance that, due to the usual adverse selection and moral hazard problems, would not be provided by (or would be severely limited in) an unregulated private market economy (Hepple 1986; Agell and Lommerud 1992). Labor market rigidity may in fact be part of an income insuring mechanism whereby workers' incomes are shielded in a variety of ways from market forces. As in other insurance markets, insurance in the labor market may have adverse allocative effects, on both the labor demand and labor supply sides of the market. It is possible that in the face of the macroeconomic shocks mentioned earlier, the "fairness" and insurance provided by institutions in much of Continental Europe and Australia in the 1980s and 1990s have had especially large allocative effects leading to higher unemployment. ${ }^{21}$

From this perspective, one may wonder why the US has much less income-insuring institutions than other countries. Supply-side effects may well be important, since better developed financial markets and easier geographical mobility can make collective insurance mechanisms less necessary for American workers. On the demand side, insurance is likely to be a normal good and US wage levels (at least in PPP terms) are at least as high as those elsewhere (Table 2). So, if Americans do have less demand for insurance, it is not likely to be due to income effects, and labor market flexibility may reflect the same factors that have resulted in such a low rate of unionization in the United States. The origins of this difference date back to the $19^{\text {th }}$ century when, it has been argued, individuals perceived much greater opportunity for upward social mobility and wealth accumulation in the US than in Europe (Pelling 1960). If these perceptions were in fact held, then it is easy to see why collectivist policies of social democratic trade unionism and welfare capitalism took hold to a lesser extent in the United States than in Europe. It is possible that American workers perceive more opportunity for

${ }^{21}$ It is also possible that equalizing wages across industries, which is a goal of encompassing collective bargaining agreements, may raise economic welfare by equalizing the marginal revenue product of labor across different sectors (Freeman 1994). 
upward mobility and thus, at a given wealth level, have less demand for insurance. Ultimately, however, the sources of institutional differences are immaterial to our analysis if, as is likely, they are deeply rooted in history. In most of our work we view US-other country differences in labor market institutions during the $1970-95$ period as having been predetermined, and only briefly discuss institutional changes and reform tensions.

If institutions are meant to smooth out labor income shocks, they can do so in a variety of ways. Most obviously, unemployment insurance makes job loss less painful for workers, shifting the burden of labor reallocation in the face of shocks to a central pool of funds, and tends to reduce search effort and increase reservation wages. The implications of employment protection legislation (EPL) for wage and employment outcomes are less obvious, but such institutions can also be viewed as meant to provide insurance (Bertola, 2000). The EPL provisions summarized in our data have a similar character, but very different intensity across countries (see Bertola, Boeri, and Cazes 2000 for a recent review). As regards termination of individual employees, workers must be given reasonable notice or financial compensation in lieu of notice, and are granted rights to appeal against termination, sometimes stipulating reinstatement with back pay when the appeal is successful. As regards collective dismissals, legislation often mandates administrative procedures, involving formal negotiations with workers' organizations and with local or national authorities. Such EPL provisions reduce the likelihood of job loss, and shift reallocation costs from workers to employers. Theory suggests that employers should refrain from shedding labor in downturns when firing is costly, and also refrain from hiring in upturns. Hence, more stringent EPL should be associated with smoother dynamic employment patterns, but its contrasting effects on employers' propensity to hire and fire yield an a priori ambiguous impact on average employment and wages. When employment is averaged across aggregate cycles, theory suggests that, at given wages, EPL should not significantly bias it away from what would be implied by standard static labor demand models.

Empirically, however, wage outcomes are not unrelated to the stringency of EPL. The same countries featuring high EPL (and stable aggregate employment) also tend to display 
compressed wage distributions, and relatively stable wage dynamics for individual workers. In our data set, the simple correlation between the EPL indicator and the 50-10 log wage differential is negative, and has absolute values of about 0.75 in the 1985-90 and 1990-95 periods, when wage information is available for most countries. The negative correlation between wage inequality and the active labor market policy indicator in our data set is similarly strong. From a theoretical point of view, it is not surprising that relative wage variation should be heavily constrained in the same markets where EPL is most stringent. Quantitative firing restrictions, in fact, could hardly be binding if wages were completely unrestrained over time for a given individual: in response to the labor demand shocks that EPL are meant to protect workers from, wages could fall so as to make stable employment profitable, or to induce voluntary quits. Hence, limiting the freedom offered to employers and workers in setting wages gives force to quantity constraints.

Like EPL, minimum wages and other forms of wage compression need not reduce aggregate employment, which is ultimately determined by average wages, and may be favorably affected by government-labor-management coordination of aggregate wage-setting. Moreover, ALMPs may serve to counter the positive effect that high wage floors would otherwise have on unemployment rates. However they should tend to reduce relative employment rates for lowproductivity workers, at least assuming firms are on their marginal revenue product of labor schedules (Blau and Kahn 1999; Kahn 2000). Even here, there are policies or behavioral responses that may to some degree undo the disemployment effects of institutional interventions like minimum wages or collectively-negotiated wage floors. These include not only ALMPs, which as we noted above are inversely correlated with wage inequality, but also public employment, which may be an especially strong factor in Scandinavia (Bjorklund and Freeman 1997; Edin and Topel 1997; Kahn 1998) and in Germany as well (Blau and Kahn 2000b). In addition, school enrollment among young adults is more prevalent in more heavily unionized countries, while young adults' relative wages are high and relative employment low in such 
settings (Kahn 2000). In an economy with scarce jobs, the opportunity cost of school may be low. $^{22}$

\subsection{Institutions and Shocks: Time-Invariant Institutional Measures}

Labor market institutions may be generally meant to protect individual workers (or labor as a group) against market forces, but they also have important implications for dynamics at the macroeconomic level. Similar shocks can have very different effects in countries with different institutions. In the aftermath of the productivity growth slowdown of the 1970s and 1980s, for example, extensive collective bargaining may have kept real wages rising in many European countries, while in the US, with its lack of unionization, real wages fell. Similarly, high wage floors or greater employment protection of incumbents in Europe may have made the labor market accommodation of the baby boom generation more difficult than in the US. ${ }^{23}$

Conversely, the same institutions may have different effects in different environments, as we sometimes observe important trends in labor market performance (e.g., wage dispersion increases in some countries, or employment decreases in other countries) without large changes in institutions (Bertola and Ichino 1995; Ljungqvist and Sargent 1998). This reasoning provided the basis for Blanchard and Wolfers' (2000) models where shocks and institutions were interacted in explaining the evolution of unemployment over the 1960-95 period. In this section, we further explore these relationships using the institutional data summarized in Tables 4 and 6.

UI replacement rates, UI duration, collective bargaining coverage, union density, employment protection, and labor taxes are expected to interact positively with macro shocks that raise unemployment. For example, if there is disinflation, anything that makes nominal

\footnotetext{
${ }^{22}$ This relationship is predicted in a theoretical paper by Agell and Lommerud (1997).

${ }^{23}$ Of course, those involved in setting wage floors may well take the youth population into account and adjust their wage policies to limit the number of people priced out of the labor market. This can be accomplished by not aggressively raising the floor underneath wages. But if insiders dominate wage determination, as has been emphasized in many analyses of unemployment in Continental Europe, they may be relatively unconcerned about how many young people are without jobs. If the young are the children of the adults, and less productive, the wagebill-maximizing strategy of a centralized union can imply less than full accommodation of young cohort fluctuations.
} 
wages rigid will amplify its effect on unemployment. Conversely, if there is an acceleration of inflation, anything that keeps nominal wages rigid will amplify the unemployment-reducing effects of the rise in inflation. ${ }^{24}$ The variables are signed so that a positive value is expected to raise unemployment. Therefore, active labor market policies ${ }^{25}$ and coordination have been multiplied by minus 1 (active labor market policies help reduce unemployment, and coordination of wage-setting is believed to result in wage restraint as unions take into account the effects of their wage bargains on all workers).

Looking at Table 6, which contains the data for the youth sample (Table 4 for the whole sample is quite similar), we see that the United States has: less generous UI benefits, shorter UI duration, less collective bargaining coverage, less union density, lower labor taxes, and less employment protection than the other countries. These differences would all imply that similar adverse macro shocks would raise the US unemployment rate by less than in the other countries. However, the US also has less coordinated wage setting and less generous active labor market policies, which would imply a larger effect of macro shocks for the US unemployment rate than for other countries' unemployment rates. Therefore the ultimate effect of interactions between shocks and institutions on the US unemployment rate in relation to that in other countries is an empirical question.

Table 9 reports results obtained when shocks and institutions are allowed to interact, i.e. when the functional relationship unemployment $=\mathrm{f}($ shocks, countries $)$

\footnotetext{
${ }^{24}$ It is easy think of mechanisms linking real wage rigidity to collective bargaining coverage, union density, employment protection, and UI systems. Labor taxes may influence unemployment rates through their effect on wage-setting practices (Daveri and Tabellini 2000). More importantly for our purposes, labor income taxation can affect the after-tax impact of non-employment benefits, and therefore interact with shocks similarly to the UI replacement rate variable (Blanchard and Wolfers 2000).

${ }^{25}$ Nickell (1997) instrumented active labor market policy because it is likely to increase in response to unemployment, and we use the instrumented value here, as did Blanchard and Wolfers (2000) as well. Active labor market policy is defined as spending per unemployment worker as a fraction of output per employed worker.
} 
is not separable and features "shocks*institutions" terms.

In order to conserve degrees of freedom, following Blanchard and Wolfers (2000), we estimate the following specific form of equation (2):

$$
\mathrm{U}=\left(\Sigma_{\mathrm{i}} \mathrm{a}_{\mathrm{i}} \mathrm{S}_{\mathrm{i}}\right)\left(1+\Sigma_{\mathrm{j}} \mathrm{b}_{\mathrm{j}} \mathrm{I}_{\mathrm{j}}\right)+\sum_{\mathrm{k}} \mathrm{d}_{\mathrm{k}} \mathrm{C}_{\mathrm{k}}+\mathrm{e}
$$

where $\mathrm{U}$ is unemployment rate, $\mathrm{S}_{\mathrm{i}}$ is the $\mathrm{i}^{\text {th }}$ shock (the list includes a Portuguese revolution dummy), $I_{j}$ is the $\mathrm{j}^{\text {th }}$ institution (in terms of deviations from the sample mean), $C_{k}$ is the kth country dummy, and e is an error term. Each institution is allowed to interact separately with the same linear combination of the shocks. This model is estimated using nonlinear least squares.

The first set of results in Table 9 shows the basic interaction model without time dummies and with the youth population share as one of the shocks. Overall, the results are quite credible. Each shock is found to have a positive effect on unemployment, with the exception of youth share which has a small and insignificant negative effect. Seven of the eight institutional variables have the expected positive interaction effects; the exception is the collective bargaining interaction where the estimated coefficient is negative and insignificant. ${ }^{26}$ Moreover, the model shows small and insignificant autocorrelation.

To illustrate the interaction between shocks and institutions, consider the average effect on unemployment of a one percentage point increase in disinflation. This effect is 3.22 percentage points in the non-US countries shown in Table 1, but only 1.62 percentage points in the US. This suggests much more nominal wage responsiveness to changes in inflation in the US than in the other countries.

Finally, and most importantly, the model explains $50 \%$ of the divergence between the unemployment rates in US and the other countries over the 1970-96 period. ${ }^{27}$ Recall from Table 8 that the corresponding model without institutions explained only $11 \%$ of the divergence. Thus,

\footnotetext{
${ }^{26}$ We tested and accepted the hypothesis that youth share had the same interaction effects as the other shocks.

27 The non-US figure is the average of the individual countries' predicted unemployment rates rather than the predicted unemployment rate at the average of the countries' explanatory variable values. This procedure is followed because of the nonlinearity of the interaction models.
} 
a large portion of the reversal of unemployment fortunes between the US and the other OECD countries appears to be due to the interaction between the laissez-faire labor market institutions in the US and the macroeconomic shocks of the 1980s and 1990s.

The other models in Table 9 show what happens when we add period dummies and/or replace the youth share variable with the more exogenous previous births measure. With time effects included, the impact of youth share or previous births becomes significantly positive (as in the models in Table 8), and the effects of the macro shocks become smaller. There continues to be no evidence of autocorrelation in the interaction models. Most importantly, the interaction models continue to explain a high portion (48-63\%) of the US-other country divergence in unemployment rates.

Table 9 shows that the shocks-institutions interaction framework can account for much of the 1970-95 changes in the US unemployment rate relative to the other OECD countries. As in Blanchard and Wolfers (2000), macroeconomic shocks alone can explain only a relatively small portion of the cross-country developments. Moreover, the demographic indicators, which we have added to the Blanchard and Wolfers model, are found to play a significant role, especially when period effects are included.

As we noted earlier, reasonable objections can be raised to the assumption that these macroeconomic and demographic shocks are exogenous factors affecting unemployment. As a further check on the basic shocks-institutions framework, we reestimated our basic model, shown in equation (3), replacing the shocks with period dummies. We included interactions of a linear combination of the period effects with each of the institutions, as well as period main effects. This specification allows all countries to be affected by the same world-wide shocks, and requires no assumptions about the exogeneity of country-specific shocks or even about which specific shocks are important enough to include in the regression. However, the inclusion of the period-institution interaction terms does permit each country's institutions to filter common shocks in potentially different ways. Using this model, we predict that unemployment should have risen by 6.26 percentage points more in non-US countries included in Table 9 than in the 
US over the $1970-1996$ period. This is $77 \%$ of the actual divergence between the non-US and the US unemployment rate over this period.

Again, the shocks-institutions model is strongly supported. However, in this case, part of each country's response to the world-wide shocks may involve different macroeconomic policies as well as different wage responses implied by the labor market institutions, and the model allows for the possibility that institutions can affect policy responses. For example, highly unionized economies may have a different monetary policy response to global events from that in less unionized countries (see Cukierman and Lippi, 1999, and their references for theoretical and empirical models of monetary policymaking in the presence of centralized unions). The higher share of the unemployment divergence between the US and the other OECD countries explained by the "period effects-institutions" model (77\%) than by the measurable shocksinstitutions models presented in Table 9 (48-63\%) may lend support to the idea that institutions affect macroeconomic policies, as well as helping to determine the labor market effects of given policies. $^{28}$

\subsection{Institutions and Shocks: Time-Varying Institutional Measures}

As we noted above, institutions have changed in several countries. In this subsection, we attempt to take into account the effects of these changes in explaining relative United States unemployment levels over time. We were able to construct time-varying measures of five of the eight institutions considered earlier. First, we use the one-year UI replacement rate employed by Blanchard and Wolfers (2000). This is a time-varying measure which was constructed from OECD annual data from 1961-95, and thus covers the entire period. Second, we use Blanchard and Wolfers' (2000) time varying employment protection index, which the authors constructed

\footnotetext{
${ }^{28}$ The fact that the period-institutions model explains a larger share of the US-other country unemployment divergence than the corresponding models in Table 9 with measurable shocks might suggests that the former model fits the data better than the latter. However, we must bear in mind that this decomposition refers to 10 countries and 2 periods, while the regression has 103 data points. The overall goodness of fit of the period-institutions model and the fourth specification of the measurable shocks-institutions model shown in Table 9 (i.e., including country and year dummies and the incidence of births 15-24 years previously) is quite similar, with residual standard deviations of 0.0143 for the period-institutions model and 0.0141 for the measurable shocks-institutions model.
} 
from a variety of sources (see Addison et al., 2000, for careful discussion of these and other relevant data sources). When there were missing years from their measures, Blanchard and Wolfers either interpolated or assumed no change if there was no information on a given period. Third, we added three time-varying measures not used by Blanchard and Wolfers. These included union density, taken primarily from Visser (1996), and collective bargaining coverage and coordination, taken from OECD (1997). ${ }^{29}$ Visser's (1996) union density measures were usually available annually from 1970 to 1993 . When there was missing data, we interpolated, and we assigned the 1970 value to periods before 1970, and the 1993 value to the 1995 period. The collective bargaining coverage and coordination variables were generally available for 1980, 1990 and 1994. Again, we used interpolation and assigned the 1980 values to periods before 1980 and the 1994 values to 1995 . These instances of imputation illustrate some of the difficulties in accounting for institutional change in a regression context.

Appendix Table A1 illustrates the changes in these institutions for the US and for the nine other countries included in Table 9. In each case, since 1970 institutions have changed, on average, in ways that one might reasonably expect to lower the US relative unemployment rate. ${ }^{30}$ First, UI replacement rates rose both in the US and elsewhere, but increased by far more outside the US (16.89 versus 3.18 percentage points). Second, despite recent reductions in the strength of employment protection in several non-US countries (OECD 1999), the employment protection index was constant in the US but rose slightly on average from 1970 to 1995 outside the US. Third, collective bargaining coverage fell in the US and elsewhere, with a larger fall in the US. Fourth, union density was roughly constant outside the US (a fall of 0.07 percentage points) but fell by 11.17 percentage points in the US. Finally, coordination fell slightly outside the US

\footnotetext{
${ }^{29}$ We thank Jonas Pontusson and David Rueda for providing additional union density data beyond that in Visser (1996).

${ }^{30}$ Benefit systems became less generous in the 1980s and 1990s in specific countries such as the UK and the Netherlands (Nickell and van Ours 2000), and collective bargaining coverage fell dramatically after 1991 in New Zealand (Maloney 1994) and 1980 in the UK (OECD 1997). However, on average across the nine non-US countries, institutions have changed since 1970 in ways that should have raised their unemployment rates relative to the US.
} 
(recall that the variable has been multiplied by -1 to reflect the idea that more coordination is expected to lower unemployment) and stayed the same in the US. ${ }^{31}$

Appendix Table A2 contains selected regression results from unemployment rate equations that allow time-varying institutions. Country dummies are included, so the effect of institutions only reflects the impact of changes within countries. We do not include time effects in order to give shocks their best chance of explaining the results, although the findings were not greatly affected by the inclusion of period dummies. The main effects of the institutions are typically positive, as one would expect (recall that the effects of employment protection are theoretically ambiguous), although the interaction effects are mixed. After estimating the models in Table A2, we used them to examine the degree to which they can account for the divergence of unemployment in the US vs. other countries over the 1970-95 period. First, the model without interactions accounts for $29.8 \%$ of the rise in relative unemployment in the other countries, a figure that is more than double the amount explained in the corresponding model in Table 8 that assumed time-invariant institutions. Of this $29.8 \%, 12.4$ percentage points were associated with the less favorable macro shocks and demographics in the other countries, and the remaining 17.4 percentage points were due to the less employment-favorable institutional changes in these countries. Second, and similarly to the results in Table 9 that assumed time-invariant institutions, when we allow shocks and institutions to interact, and include institutional main effects as well, the model explains $63.0 \%$ of the unemployment divergence. ${ }^{32}$

The implications of these models that use constructed, time-varying measures of institutions are twofold. First, institutional changes have raised unemployment outside the US relative to the US by a modest amount that is slightly larger than the effects of macro shocks and

\footnotetext{
31 The coordination measure clearly does not take into account the fact that even in the US, bargaining became less coordinated in the 1980s and 1990s (Katz 1993).

32 When we used youth share instead of prior births, we obtained results very similar to those discussed above. And, as noted, adding period effects led to qualitatively similar decomposition results as well. Note that the interaction model in Table A2 includes institutional main effects as well as country dummies. In the models reported by Blanchard and Wolfers (2000) that allowed employment protection and UI replacement rate to vary over time, the authors did not include main effects for these variables. However, in private communication with us, Olivier Blanchard stated that when they included main effects, they had little impact on unemployment.
} 
demographics. Second, as was the case in models that assumed time-invariant institutions, the interaction between labor market institutions and macro and demographic shocks remains very important in accounting for the divergence in unemployment between the U.S. and other countries since 1970 .

\subsection{Wages and Wage Inequality}

Recall that we have interpreted our interaction models as suggesting that US real and relative wages are more flexible in the face of macro and demographic developments than are those of other OECD countries. From the simple theoretical perspective of Section 2, the negative employment impact of shocks should be particularly strong when they would tend to increase the dispersion of earnings in an unregulated labor market and this outcome is forestalled by labor market institutions. Structural changes such as increasing international competition and skillbiased technological progress are potentially important in this respect, and need not be captured appropriately by the macro shocks considered above.

To obtain some more evidence on this notion, we have estimated linear unemployment models with shocks augmented by including median male log real wage levels and the male 50$10 \log$ wage gap on the subsample considered in Tables 2 and 3. Like all our models, this specification is not fully structural. Yet the impact of adding wages and wage inequality directly can provide further evidence on the basic perspective we adopt in interpreting the data. We have regressed unemployment on macro shocks, youth share or prior births/prior population, median male log wages, log male 50-10 gap, country dummies and year dummies. In each case, median male wages has a positive (insignificant) coefficient, while male wage inequality has a negative, significant effect on unemployment. Among the shock variables, only the change in inflation and the real interest rate are significant, and much less strongly so than the wage-inequality indicator. $^{33}$

\footnotetext{
${ }^{33}$ An interesting paper by Higgins and Williamson (1999) shows that income and earnings inequality are tightly related to demographic growth variables in a World Bank panel data set including observations from less developed countries. Such a link would be readily implied by a data generating process where wage distributions are generated
} 
In the wage sample, there were seven countries with data for 1975 and 1995: Australia, Finland, France, Japan, Sweden, the UK, and the USA. Unemployment in the US fell from $7.02 \%$ in $1975-9$ to $5.55 \%$ in $1995-6$, while in the other countries it rose from $3.96 \%$ in $1975-9$ to $9.30 \%$ in $1995-6$. Thus, unemployment increased by 6.86 percentage points in the other countries relative to the US. A model without wage variables explains $33 \%$ of the divergence, while one with wage variables included explains $79 \%$ of the decrease in the unemployment rate in the US relative to the other countries. These accounting results are quite similar to those in Tables 8 and 9 and give us some further confidence that wage behavior, mediated by institutions, is an important part of the explanation of US unemployment experience. ${ }^{34}$

Replacing the youth share variable with previous births left the wage and wage inequality effects the same but improved the explanatory power of the model without wages. Specifically, shocks and births explain $52 \%$ of the divergence, while adding wage data increases the explanatory power to $75 \%$. Either way, macro shocks and wage behavior together account for most of the decrease in unemployment in the US relative to other countries. Of course, the wage variables are clearly endogenous as previously argued, and this analysis should only be seen as suggestive evidence supporting the idea that wage behavior may be an important part of the US unemployment story. ${ }^{35}$

\subsection{Persistence and Hysteresis}

We consider next the possibility that changes in inflation, or more generally in aggregate demand, may affect unemployment persistently through mechanisms of hysteresis. One such

\footnotetext{
by similar wage-age curves and different cohort sizes. In our data, the correlation between wage inequality and the 15-24 share of the population (or the lagged birth rate) is indeed positive (about 0.5). The coefficient on wage inequality, after controlling for at least some demographic characteristics (which are not significant), gives an indication of the impact of wage-compressing labor market institutions on unemployment.

${ }^{34}$ Using the second specification in Table 9 (i.e., including youth share and time effects), we explain $71 \%$ of the 1975-95 divergence between the unemployment rate in US and these six other countries. This is a very similar effect to the one reported here based on a model with wage behavior replacing the institution-shock interactions.

35 It would be interesting to estimate the determinants of wage inequality in the same shocks-institutions framework we used for unemployment. However, the small number of observations for wages (58 vs. 103 for the unemployment analysis), precludes estimating such a model.
} 
mechanism, emphasized by Ball (1997 and 1999), results from the notion that the long-term unemployed may not search very hard for jobs. In this view, when unemployment becomes long-term, it takes more and more overall unemployment to establish the downward real wage pressure needed to induce firms to hire more labor. If this is true, then not only will falling inflation raise the actual unemployment rate. A decrease in inflation, if severe and long-lived, can also lead to a higher eventual unemployment rate, and the effects of aggregate demand on unemployment will be understated by a model that considers only the impact on current unemployment.

Ball (1997 and 1999) uses this reasoning to suggest that the favorable performance of natural unemployment rate in the United States over the 1980s and 1990s is tied to its shorter deflationary period in the 1980 s and its more expansionary monetary policy in the 1990 s. Since the unemployment effects of disinflation become more severe the longer the potential duration of UI benefits, US unemployment outcomes should also be more favorable because of its labor market structure. Specifically, Ball (1997) constructed a measure of the natural rate and then examined how inflation and UI duration affected the 1980-90 change in the natural rate measures across 20 countries. ${ }^{36} \mathrm{He}$ did not perform an explicit accounting of US-other country differences in the changes in the natural unemployment rate, but his paper did include all of the data used, allowing us to implement this accounting now.

According to Ball's (1997) data, the natural unemployment rate in the United States fell by 1.4 percentage points over the $1980-1990$ period. In contrast, across the other 19 countries, the natural rate rose by an average of 2.32 percentage points. Thus, the natural rate rose by 3.72 percentage points more in the other countries than in the US. Somewhat surprisingly, the US had a larger fall in inflation than the other countries (8.1 percentage points for the US versus 6.41 percentage points for the other countries), suggesting that the depth of the disinflation cannot explain the US-other country unemployment comparison. However, the longest period of disinflation in the US was only 3 years, in comparison to an average of 4.32 years elsewhere.

\footnotetext{
${ }^{36}$ These are the same 20 countries used in Nickell and Layard (1999).
} 
Thus, in Ball's (1997) framework, the US disinflation allowed less time for hysteresis to set in. And of course, the US has a shorter duration of UI benefits ( 0.5 years vs. an average of 2.71 years elsewhere), again suggesting a smaller hysteresis response to disinflation in the US.

Using Ball's (1997) regression model for the 1980-90 change in the natural rate as a function of the two inflation variables only (the 1980-90 fall in the inflation rate and the square of the length of the longest period of disinflation), we predict a rise of 1.30 percentage points in the US natural rate and an increase of 2.19 percentage points elsewhere. ${ }^{37}$ Thus, the model with inflation shocks predicts that the natural rate should have risen by only 0.89 percentage points more in the other countries than in the US, or roughly $24 \%$ of the US-other country difference in the change in the natural rate (i.e. the 3.72 percentage points). However, when we add UI duration and its interactions with the two inflation variables, we predict a fall of 1.20 percentage points in the US natural rate and a rise of 2.35 for the other countries. These predictions are remarkably close to the actual changes of -1.4 for the US and 2.32 for the other countries. The shocks-institutions model in this case explains fully $95 \%$ of the US-other country difference. This reflects the facts that the US had a less disinflationary environment in the 1980s than the other countries, and that a given disinflation in the US produces less unemployment than elsewhere. Thus this exercise, using an alternative concept of unemployment and a different specification, confirms our earlier results presented in Tables 8 and 9. Namely, macroeconomic shocks explain part of the US-other country experience, but the real story is how they interact with the more laissez-faire institutions in the US. ${ }^{38}$

\footnotetext{
${ }^{37}$ Questions of endogeneity arise here, as they did in Blanchard and Wolfers' (2000) framework. Specifically, increases in the natural rate may affect macro policy. As Mankiw (1999) argues in his comments on Ball (1999), a falling natural rate may enable the government to pursue a more expansionary monetary policy. Regression results showing a negative effect of inflation on the natural rate may thus reflect the impact of the natural rate on inflation. Note that Blanchard and Wolfers' (2000) analysis of the actual unemployment rate implies the opposite reverse causality bias from the one Mankiw (1999) emphasizes. When the actual unemployment falls relative to the natural rate, we expect compensating monetary policy.

${ }^{38}$ Ball (1997) experimented with interactions between other institutional variables such as the ones we have used here and disinflation indicators but found that they did not add any explanatory power over the UI benefit durationdisinflation interactions.
} 


\section{Disaggregated Labor Market Performance}

Theory has stronger predictions for the effects of labor market institutions on the dynamics and composition of (un)employment than for its aggregate/average level. For example, as discussed above, job security provisions reduce both hiring and firing, and hence have small and ambiguous effects on average (un)employment at given wages and productivity. But high job security should unambiguously stabilize employment dynamics and lengthen both tenures and unemployment spells (Bertola 1999b).

Composition effects also have important normative/interpretation implications: while "the" unemployment rate or average real wage level may be adequate performance indicators from a macro perspective, the welfare and distributional implications of short/long term unemployment and differences in employment and wage rates across groups are clearly also very important in evaluating the success of labor market policies. Hence, a positive theory of institutional effects on labor market performance should take composition effects into account. Our work is intended to extend and corroborate existing work in this area, which has been surveyed in Bertola (1999b) and Blau and Kahn (1999).

As noted earlier, poor wage outcomes for the less skilled are America's signature labor market problem. But high employment levels may be one benefit of our downwardly flexible real wages. In this section, we document the extent to which high employment levels covary with demographic composition of the labor force.

We have been able to assemble long-run population and employment information for demographic sub-groups in a number of countries (these data are from country specific sources, hence not fully comparable; see the Data appendix). Table 10 shows for our sample of 10 countries with data for 1970-74 and 1995-6 what happened to unemployment and employmentto-population ratios by age and gender over this period. It shows that not only did the overall unemployment rate fall in the US relative to other countries, but so too did the unemployment rate of every age-gender group. And the employment-to-population ratios of each group also rose in the US relative to other countries. Finally, and most importantly, the last five lines in 
Table 10 indicate that relative employment-to-population ratios of young people, older people, and prime-age women also rose in the US relative to other countries. That is, over the 1970-96 period, the relative employment propensity of low wage workers (women and youth) and/or workers with below average labor force attachment (women, youth, and older workers) rose in the US compared to the other countries. This outcome is exactly what the "Unified Theory" would predict in light of the US's more laissez-faire institutions. Of course, the large increases in unemployment in the non-US countries could have by themselves produced such changes in relative (un)employment, if these low wage and less-than-fully-attached workers are last in a queue of jobseekers. Our evidence seems to be consistent with this last conjecture, since the relative employment-to-population ratios of both younger (age 15-24) and older individuals (age 55 and over) compared to those age 25-54 are countercyclical for both men and women.

To shed light on the causes of these changes in relative US employment, we have estimated two kinds of regression model. First, using the male prime age/youth employment differential as an example, we have estimated models such as:

(4) Ln (epopmen 2554/epopmen 1524) $=\mathrm{f}$ (overall unemployment, youth share, country dummies, period dummies, post-Portuguese revolution dummy).

By estimating (4), we can determine whether overall economic and demographic conditions can explain the US-other country differences in the changes in relative employment. ${ }^{39}$ Second, we augment (4) by interacting the Blanchard-Wolfers (2000) time-invariant institutions with unemployment and youth share. ${ }^{40}$

\footnotetext{
${ }^{39}$ We recognize that the overall unemployment rate is endogenous; however, one should view the results of equation 2) in an accounting sense-is the United States' fall in relative overall unemployment over the 1970-95 period sufficient to account for its rise in youth relative employment? We tried models like our original equation 1) for relative employment (with the underlying macro shocks replacing the overall unemployment rate), but unfortunately we were not able to achieve convergence of the nonlinear least squares estimator.

${ }^{40}$ We obtained qualitatively similar decomposition results to the ones reported below when we used time-varying institutions, as described in Section 6.3.
} 
We now briefly summarize the decomposition results. The strongest results are for youth and older men. Taking first the example of the employment gap between prime age (25-54) and young (15-24) men, a model that includes only unemployment and youth share (plus the country, post-Portugal revolution dummy and period effects) explains $58.2 \%$ of the divergence between other countries and the US in this gap. Replacing youth share with the previous birth incidence raises the fraction explained to $66.8 \%$. The US has better overall unemployment performance and a more rapidly falling youth population share and previous birth incidence, both of which contribute to the more slowly rising male prime age-youth employment gap in the US. However, when we allow the effects of overall unemployment and youth share or birth incidence to interact with our eight time-invariant institutional measures, we are able to explain $94.1-111.5 \%$ of the diverging employment gap. While these interactions do not have consistent sign patterns, the decomposition results indicate that excluding these interactions (i.e., forcing unemployment and demographic developments to have the same effect for all the countries) causes us to underpredict the rising employment gap in non-US countries relative to the US. Other countries' interventionist institutions interact with their unemployment rate and youth share to accentuate employment differences between young and prime age men, relative to the US.

We obtain largely similar results for the female employment gap between 25-54 year olds and 15-24 year olds, as well as the gap between prime age men and older men. In each case, the model without interactions is able to explain $47-60 \%$ of the rising other country-US difference in employment gaps, but allowing interactions with institutions greatly increases our explanatory power to $91-138 \%$. However, for prime age vs. older women the model does at least as well with no interactions as with interactions. And for prime age men vs. prime age women, the model does much better without interactions than with them. Clearly, we have not accounted for all possible institutions, most notably the characteristics of the retirement system (Gruber and Wise 1997). And male-female employment differentials are especially likely to be affected by differential changes in female labor supply which may not be captured well by our institutional measures. However, overall youth employment appears to behave in ways that conform with the 
"Unified Theory", and our results suggest that any attempt to imitate European institutions could have an especially large negative effect on American youth employment.

The broad and quite sensible message of our data is that in interventionist countries the employment and unemployment rates of youth and older groups bear the brunt of aggregate fluctuations and trends, while prime age males are protected as "breadwinners" by labor market institutions. Our findings for youth are similar to those obtained by Kahn (2000) who found that during the 1985-94 period, all else equal, greater union coverage was negatively associated with youth relative employment, where the latter was defined in a regression-adjusted context based

on micro data. ${ }^{41}$ Moreover, he found that greater union coverage was positively associated with school attendance of those age 18-29, a possible outlet for those encountering difficulties finding a job.

\section{Recent US Labor Market Dynamics and Robustness Checks}

In this final substantive section of the paper we outline the lessons of our theoretical perspective and empirical results for current developments, especially as regards the remarkably good recent performance of the US labor market. Then, we explore the robustness of our empirical results on more recent and different data, and discuss their implications for the interpretation of current US experience.

\subsection{Implications for recent US developments}

Much of our work has focused on reinterpretations and extensions of Blanchard and Wolfers'(2000) results, with particular attention to the contrast between the long-run experiences of the US and other countries. This contrast, which is quite sharp in terms of broad trends over the past few decades, may in some respects be even more dramatic at the turn of the millennium. In the year 2000, the American labor market was enjoying unemployment rates as low as 3.9\%. 
At the same time, Japan's unemployment rate edged towards the unprecedented (for that country) 5\% level, and some European countries such as France, Italy, Belgium and Spain found it difficult to decrease their unemployment rates substantially below two-digit levels (OECD 2000). While overall European unemployment levels remain stubbornly high, there have been some reductions (albeit from very high levels) in France (2.8 percentage points from 1996 to August 2000), Italy (1.4 percentage points from 1998 to July 2000), Sweden (4.3 percentage points from 1997 to August 2000), Spain (7 percentage points from 1995 to 1999), and the Netherlands (3.6 percentage points from 1995 to 1999). ${ }^{42}$ These reductions may represent the effects of policy changes (see e.g. Nickell and Van Ours, 2000, on the UK and the Netherlands) or they may represent moves back a more "normal" unemployment level for a given country. However, the overall unemployment rate in the European Union only came down modestly from $10.7 \%$ in 1995 to $9.2 \%$ in 1999 ; at the same time, the US rate fell from $5.6 \%$ to $4.2 \%$ during the same period, a comparable decline. ${ }^{43}$

Can the recent developments in the US be understood in the context of the framework put forward in this paper? As shown in Section 3, broad long-run labor market trends (after removing country- and period-specific effects) display a tradeoff between unemployment and wage inequality. Consistent with this, the US could be viewed as trading relatively low levels of the unemployment for relatively high levels of wage inequality. Slow US real wage growth is

\footnotetext{
${ }^{41}$ Specifically, education and marital status were controlled for.

42 This information is taken from the BLS web site and OECD (2000).

${ }^{43}$ Freeman and Schettkat (2000) argue that percentage point differences or changes in the unemployment rate level (as opposed to relative changes, where for example a change from 5 percentage points to 4 percentage points would be $20 \%$ reduction) are the proper measure of changes in the demand for labor. To see this, note that: $\mathrm{E} / \mathrm{P}=(\mathrm{LF} / \mathrm{P})(1-\mathrm{UR})$, where LF is the labor force and UR is the fraction of the labor force that is unemployed. Then if the labor force participation rate is constant and if UR is relatively small: $\ln (\mathrm{E} / \mathrm{P})=\mathrm{k}+\ln (1-\mathrm{UR}) \approx \mathrm{k}-\mathrm{UR}$, where $\mathrm{k}=\ln (\mathrm{LF} / \mathrm{P})$. Therefore changes or differences in $\ln (\mathrm{E} / \mathrm{P})$ are approximately the same magnitude and opposite in sign to changes or differences in the unemployment rate (Freeman and Schettkat 2000, p. 15). This argument
} 
consistent with the milder tradeoff which we detected between unemployment and wage levels.

Over the 1990s, however, real wage growth has been strong for all American workers, and somewhat stronger for those at the bottom of the earnings distribution than for others. For example, Deavers, Lyons and Hattiangadi (1999) report that median real hourly wages (CPIcorrected) rose about 7-8\% between 1989 and 1999, with virtually all of the increase coming after 1996. Moreover, wages at the $20^{\text {th }}$ percentile rose by $11-12 \%$ during this period, again with most of the increase coming after 1996 , while wages at the $80^{\text {th }}$ percentile increased by $9 \%$ from 1989 to 1999.

These data indicate that in the 1990s, the US has had falling unemployment, rising overall wages and, by some indications, falling wage inequality. The theoretical and empirical perspective developed in this paper would then point to unusually favorable period-specific shocks, rather than to movements along a stable tradeoff, as the source of favorable employment developments during this time for the US. And it would point to relatively favorable countryspecific developments as the reason why the US unemployment rate has been declining further in relation to those of many other OECD countries.

To flesh out this implication, and to test the robustness of our empirical strategy, we have recalculated the Blanchard-Wolfers shock variables on recent OECD Business Sector data. ${ }^{44}$ The data extend to 1998 and 1999 for most countries but are not available for earlier periods in some countries, presumably because of data revisions at OECD. ${ }^{45}$ Table 11 reports updated

\footnotetext{
implies indeed that the reduction in unemployment corresponds to similar increases in the demand for labor in Europe and in the US.

${ }^{44}$ The data are those available in the 2000:1 edition of the OECD Statistical Compendium CD-Rom. We are grateful to Justin Wolfers, who sent us the original program for computing the macro shock indicators, and to Julian Messina and Thomas Steinberger, who organized the updated data and prepared the data set.

${ }^{45}$ The version of the OECD Business Sectoral Database available to us does not contain a capital stock series (KBV) for Australia. GDP business sector data (GDPB) are missing pre-1987 for the UK and pre-1970 for Finland, and the long term interest rate (IRL) is missing for pre-1985 Ireland. Pre-1978 unemployment rate data for Australia were also not available from the CD-ROM.
} 
summary statistics for the US and the available sample of non-US countries with information for both the 1990-94 and 1995-present periods, in the same format as Tables 4 and 6. In the more recent period, the US labor market does appear to feature lower unemployment and faster total factor productivity growth than in samples which stop in 1996. Specifically, favorable shocks come to the US labor market in the form of faster total factor productivity growth: the tfp measure computed from the available OECD data grows at roughly $2 \%$ over the second half of the 1990 s, as opposed to $0.15 \%$ in the Blanchard-Wolfers data set. This feature of the OECD updated data reflects both the newly available 1997 observation, and revisions of the 1995-96 data used by Blanchard and Wolfers. It is quite consistent with recent detailed discussions of the determinants of rapid labor productivity growth in the current US experience (see Oliner and Sichel, 2000, and their references). We also report in the Table yearly information on unemployment and shocks for the US over the 1995-99 period, and discuss them in the context of our model below. ${ }^{46}$

Table 11 reports differences of unemployment and shock values for the US and the average of the available comparison group of 15 countries over the early-1990s and late-1990s periods. The Table shows that the unemployment rate fell in the US by 1.65 percentage points while falling by only 0.05 percentage points elsewhere. Changes in labor demand and productivity growth favored the US, while changes in real interest rates and inflation favored the comparison group. Finally, youth share and prior births fell everywhere, with larger declines in the comparison countries. Thus, the overall shocks moved in potentially offsetting ways.

\footnotetext{
${ }^{46}$ The business-sector capital stock data was missing in the OECD source for 1998 and 1999. The shock variables that need such information are computed for these two years extrapolating the series on the basis of the average $0.79 \%$ quarterly growth rate of the capital stock over the whole sample, which is close to capital growth rate in the last available period (in the fourth quarter of 1997, the capital stock increased by $0.84 \%$ ).
} 
In an attempt to explain the US experience in the late 1990s both absolutely and relative to the other countries, we use the shocks-institutions model from Table 9 that excludes year dummies and uses the prior births demographic variable (which is arguably more exogenous than the youth share). We exclude period dummies in light of our discussion that they may partially include the effects of the shocks, although the basic results were similar when we included period effects. As discussed below, we have also estimated models on the updated OECD data with similar results, but we use the original Blanchard-Wolfers regression sample from Table 9 to compute regression coefficients because this is a larger sample than is available in the corrected data.

Table 11 shows how far the model can go in explaining the remarkable US performance in the late 1990s. Stated simply, the answer is "not very far." Specifically, the model predicts that unemployment should have fallen by 0.84 percentage points in the other countries and should have stayed virtually the same in the US. Further, using annual data from 1995-1999 in the US to form predicted unemployment rates, Table 11 shows that the model overpredicts US unemployment in each case and underpredicts the decline between 1995 and 1999. While our earlier discussion indicates that the basic regression framework does a good job of explaining developments in the US relative to other countries between the 1970s and the 1990s, the post 1995 decline in US unemployment appears to be due to US-specific events not captured by our shock variables. Of course, if the true effect of productivity growth is larger than we have estimated, then the apparent acceleration in productivity growth in the US could help explain the late 1990s fall in US unemployment. As discussed by Ball and Moffitt (2001), if wage expectations in the US have lagged the recent rise in productivity growth, then we would expect falling unemployment. However, our wage-setting framework suggests that the same rise in 
productivity in much of Europe would produce an even greater fall in unemployment there to the extent that wages are more rigid. Thus, it must be the case that productivity growth has greatly taken off in the US relative to other countries if this is to be the explanation for the especially low unemployment in the US in the post-1995 period.

Table 12 provides more evidence on the superior US unemployment performance in the 1995-99 period by showing unemployment residuals for the US from various specifications of the basic shocks-institutions interaction model. While US residuals in the pre-1995 years are sensitive to alternative specifications, the residual for 1995-99 is always negative and large in absolute value (ranging from -0.0161 to -0.0238 ) relative to the actual unemployment rate of .0494. Again, we conclude that the most recent five years have indeed been a period in the US of remarkably low unemployment that is substantially less than one would have expected given the shocks and institutions the US has experienced.

\subsection{Robustness of the Basic Model to Alternative Data Sources}

As noted, we have constructed an updated version of the Blanchard and Wolfers (2000) data base on a subset of their countries. We have re-estimated our models on this subset with qualitatively similar results to those presented in Tables 8 and 9 . The regression coefficients are similar as are our conclusions about explaining unemployment developments between the 1970s and the 1990s. Specifically, using the prior births specification, shocks alone can explain 8-21\% of the divergence between the average unemployment rate in the US and among the 8 other countries for which data were available for 1970-4 and 1995-9 (Canada, Finland, France, Germany, Italy, Japan, Spain and Sweden). When we add institutions, we explain 25-34\% of the 
divergence. While the model with institutions does better than the shocks only model, we have seen that the model with the larger sample (Table 9) does even better than this. However, the corrected OECD data allow for a larger number of countries to be compared for 1975-95 than for 1970-95, permitting us to add the Netherlands and Norway. For this larger sample of countries, the interaction model explains up to $60.2 \%$ of the divergence between the US and the other countries' unemployment rates over the $1975-95$ period. On the original Blanchard and Wolfers (2000) data and sample, our Table 9 models explain up to $72 \%$ of the divergence over the 1975 95 period.

We have also checked the robustness of our qualitative results to use of different definitions of the unemployment rate. The OECD Statistical Compendium CD-Rom includes a series of "standardized unemployment rates," which are only available for a subset of countries and periods. Aggregated over 5-year periods, this unemployment series is available for a total of 76 observations merged with the OECD-corrected macro and demographic information. When this unemployment measure is regressed on macro shocks, lagged birth rate, country dummies, and period dummies, the model explains $21.1 \%$ of the decrease of the US unemployment rate between 1980-85 and 1995-96 relative to the available comparison group (Belgium, Canada, Denmark, Finland, France, Germany, Italy, Japan, Netherlands, Norway, Spain and Sweden). Including institutional interactions increases the portion explained to $58.3 \%$. These results are qualitatively similar to those obtained, on the same sample and with the same specification, for the unemployment measure used by Blanchard-Wolfers (2000). Thus, even though measured unemployment differs depending on which definition one uses (Sorrentino 2000), our results are robust to different definitions and, implicitly, to different sets of countries for which data are available. 


\section{Conclusions}

The comparative information collected and discussed in this paper can be brought to bear on two important issues:

- $\quad$ First, can the US sustain its current low unemployment rates, despite its relatively high rates of the 1960s and 1970s?

- $\quad$ And has the US achieved low unemployment at the expense of wage inequality, or can the US improve labor market outcomes for those at the bottom without threatening its high employment levels?

To the first question, we answer that the improvement in the US unemployment rate relative to other countries since the 1970s is partly explained by more favorable macroeconomic shocks and partly by institutional changes that were more favorable to employment in the US than elsewhere. The macro shocks may or may not continue in the future, although they did accelerate positively in the late 1990s. With its largely laissez-faire labor market, there is seemingly little room for further major institutional change toward even more flexibility in the US. To the contrary, recent concerns about low pay in the US for the less-skilled have spurred proposals for raising the minimum wage from $\$ 5.15$ per hour to $\$ 6.15$. More importantly, however, we find the superior overall unemployment performance in the US since the 1970s is largely due to the interaction between macro shocks and our laissez-faire labor market institutions. Shocks that produced $10-12 \%$ unemployment levels in Europe with its rigid wagesetting institutions and interventionist benefit systems led to much smaller increases in unemployment in the US which were eventually reversed.

Our analysis of the post-1995 period has revealed some important insights that are relevant to the question of sustainability. The shocks and institutions model appears to successfully characterize the US in international perspective until 1995. After that, the model overpredicts US unemployment. An empirical model fitted on a broad range of cross-sectional and time-series data could hardly be expected to fit a single country-period observation perfectly 
(in fact, the prediction error for the US in the 1995- period is well within the model's prediction confidence bands). The result, however, is in line with those of many other Chapters in this volume, which also find it hard to explain the exceptionally favorable character of recent US labor market performance. From the perspective of our model, something changed in the United States after 1995 that evidently did not affect the other countries to the same extent. While the technological progress associated with the internet is available world-wide, it is possible that the more flexible labor market and product market institutions in the US (Krueger and Pischke 1997) have permitted a more rapid implementation of this technology through, for example, business formation. If this is the case, then eventually, other countries may catch up here as well, as they appear to have been doing with respect to real wage levels.

To the second question we answer that, not surprisingly, high wage inequality and low wage levels are associated with low unemployment. To document this well rehearsed claim in a structured way, our empirical analysis of a long-run panel data set offers an interpretation of recent US experience in terms of policy choices along a given technological "menu" and shifts in policy menus. The relevant shifts are partly common across industrial countries and, while essentially unobservable, they may correspond to the popular notion that "globalization" and "new technologies" make it increasingly difficult for OECD countries to deliver favorable employment and wage opportunities to some of their workers. Thus, the same flexibility that allows the US labor market to absorb macroeconomic shocks with smaller changes in unemployment than occur in other countries also makes for more flexible real wages and relative wages. 


\section{References}

Addison, John T., Paulino Teixeira, and Jean-Luc Grosso. 2000. “The Effect of Dismissals Protection on Employment: More on a Vexed Theme." Southern Economic Journal 67(1): 105-22.

Agell, Jonas, and Kjell Erik Lommerud. 1992. "Union Egalitarianism As Income Insurance." Economica 59(235): 295-310.

, and 1997. "Minimum Wages and the Incentives for Skill Formation." Journal of Public Economics 64(1): 25-40.

Ball, Laurence. "Aggregate Demand and Long-Term Unemployment." 1999. Brookings Papers on Economic Activity 2: 189-236.

----------. 1997. "Disinflation and the NAIRU." In Reducing Inflation: Motivation and Strategy, edited by Christina Romer and David Romer. Chicago: University of Chicago Press, pp. 167-185.

Ball, Laurence, and Robert Moffitt. 2001. "Productivity Growth and the Phillips Curve." Paper presented at the Russell Sage/Century Foundation Conference on Sustainable Employment. Amelia Island, Florida (January 26-28, 2001).

Bertola, Giuseppe. 1998. "Labor Demand, Institutions, and Tenure Lengths." Unpublished paper. European University Institute, November 1998.

. 1999a. "Labor Markets in the European Union." Working Paper RSC 99/24. European University Institute (also ifo Studien 1/2000, pp.99-122).

1999b. "Microeconomic Perspectives on Aggregate Labor Markets." In Handbook of Labor Economics, Volume 3C, edited by Orley Ashenfelter and David Card. Amsterdam: North-Holland, pp. 2985-3028.

. 2000. "A pure theory of Job Security and Labor Income Risk." Unpublished paper. European University Institute, January.

Bertola, Giuseppe, Tito Boeri, and Sandrine Cazes. 2000 "Employment protection in industrialized countries: The case for new indicators." International Labour Review 139(1): $57-72$

Bertola, Giuseppe, and Andrea Ichino. 1995. "Wage Inequality and Unemployment: U.S. vs. Europe.” In NBER Macroeconomics Annual 1995. Cambridge, Mass.: M.I.T. Press.

Björklund, Anders, and Richard B. Freeman. 1997. "Generating Equality and Eliminating Poverty, the Swedish Way." In The Welfare State in Transition: Reforming the Swedish Model, edited by Richard B. Freeman, Robert Topel, and Birgitta Swedenborg. Chicago: University of Chicago Press, pp. 33-78. 
Blanchard, Olivier Jean. 1997. "The Medium Run." Brookings Papers on Economic Activity 2: 89-141.

-. 1999. "European Unemployment: The Role of Shocks and Institutions." Baffi Lecture, Banca d'Italia.

Blanchard, Olivier J., and Justin Wolfers. 2000. "The Role of Shocks and Institutions in the Rise of European Unemployment: The Aggregate Evidence." The Economic Journal 110(462): C1-33

Blank, Rebecca M. 1997. "Is There a Trade-Off Between Unemployment and Inequality? No Easy Answers: Labor Market Problems in the United States Versus Europe." Public Policy Brief No. 33. Levy Economics Institute.

Blau, Francine D., and Lawrence M. Kahn. 1996. "International Differences in Male Wage Inequality: Institutions Versus Market Forces.” Journal of Political Economy 104(4): 791-837.

-and-------. 1999. "Institutions and Laws in the Labor Market," In Handbook of Labor Economics, Volume 3A, edited by Orley Ashenfelter and David Card. Amsterdam: North-Holland, pp. 1399-1461.

-,and --------------. 2000a. "Do Cognitive Test Scores Explain Higher US Wage Inequality?" Unpublished paper. Cornell University, June.

--, and -------------. 2000b. "Gender and Youth Employment Outcomes: The US and West Germany, 1984-91.” In Youth Employment and Joblessness in Advanced Countries, edited by David G. Blanchflower and Richard B. Freeman. Chicago: University of Chicago Press, pp. 107-167.

Gender Pay Gap." Journal of Labor Economics.

Börsch-Supan, Axel. 1994. "Housing Market Regulations and Housing Market Performance in the United States, Germany and Japan." In Social Protection versus Economic Flexibility, edited by Rebecca M. Blank. Chicago: University of Chicago Press, pp. 119156.

Card, David, and Alan Krueger. 1995. Myth and Measurement: The New Economics of the Minimum Wage. Princeton, NJ: Princeton University Press.

Cukierman, Alex, and Francesco Lippi. 1999. "Central Bank Independence, Centralization of Wage Bargaining, Inflation and unemployment: Theory and Some Evidence.” European Economic Review, 43(7): pp.1395-434.

Daveri, Francesco, and Guido Tabellini. 2000. "Unemployment, Growth and Taxation in Industrial Countries.” Economic Policy 15(1): 49-104. 
Deavers, Kenneth L., Max R. Lyons and Anita U. Hattiangadi. 1999. A Century of Progress - A Century of Change: The American Workplace 1999. Washington, DC: Employment Policy Foundation.

Edin, Per-Anders, and Robert Topel. 1997. "Wage Policy and Restructuring: The Swedish Labor Market Since 1960." In The Welfare State in Transition: Reforming the Swedish Model, edited by Richard B. Freeman, Robert Topel, and Birgitta Swedenborg. Chicago: University of Chicago Press, pp. 155-201.

Farber, Henry S. 1986. "The Analysis of Union Behavior." In Handbook of Labor Economics, Vol. II., edited by Orley Ashenfelter and Richard Layard. Amsterdam: North-Holland, pp. 1039-89.

Flanagan, Robert J. 1973. "The U.S. Phillips Curve and International Unmployment Rate Differentials." American Economic Review 63(1): 114-31.

Forslund, Anders, and Alan Krueger. 1997. "An Evaluation of the Swedish Active Labor Market Policy: New and Received Wisdom." In The Welfare State in Transition: Reforming the Swedish Model, edited by Richard B. Freeman, Robert Topel, and Birgitta Swedenborg. Chicago: University of Chicago Press, pp. 267-298.

Freeman, Richard B. 1980. "The Exit-Voice Tradeoff in the Labor Market: Unionism, Job Tenure, Quits, and Separations.” Quarterly Journal of Economics 94(4): 643-673.

Different Rules, edited by Richard B. Freeman. New York: Russell Sage, pp. 1-28.

and Lawrence F. Katz, eds. 1995. Differences and Changes in Wages in Wage Structures. Chicago, IL: University of Chicago Press.

, and Ronald Schettkat. 2000. "The Role of Wage and Skill Differences in USGerman Employment Differences." Working Paper 7474. Cambridge, Mass.: National Bureau of Economic Research, January.

Gregory, Robert G., and Jeff Borland. 1999. "Recent Developments in Public Sector Labor Markets." In Handbook of Labor Economics, Volume 3C, edited by Orley Ashenfelter and David Card. Amsterdam: North-Holland, pp. 3573-3630.

Glyn, Andrew, and Wiemer Salverda. 2000. "Does Wage Flexibility Really Create Jobs?" Challenge 43(1): 32-43.

Gruber, Jonathan, and David Wise. 1997. "Social Security Programs and Retirement Around the World." Working Paper 6134. Cambridge, Mass.: National Bureau of Economic Research, August.

Hall, Robert. 1970. "Why Is the Unemployment Rate So High at Full Employment? " Brookings Papers on Economic Activity 3: 369-410. 
Heilbroner, Robert L., and Lester C. Thurow. 1981. Five Economic Challenges. Englewood Cliffs, NJ: Prentice-Hall.

Hepple, Bob Alexander, ed. 1986. The Making of Labour Law in Europe: A Comparative Study of Nine Countries up to 1945. London: Mansell.

Higgins, Matthew, and Jeffrey G. Williamson. 1999. "Explaining Inequality the World Round: Cohort Size, Kuznets Curves, and Openness." NBER Working Paper No. W7224.

Kahn, Lawrence M. 1998. "Against the Wind: Bargaining Recentralisation and Wage Inequality in Norway, 1987-1991." The Economic Journal 108(448): 603-645.

-. "Wage Inequality, Collective Bargaining and Relative Employment 1985-94: Evidence from 15 OECD Countries." 2000. The Review of Economics and Statistics 82(4): $564-579$.

Katz, Harry C. 1993. "The Decentralization of Collective Bargaining: A Literature Review and Comparative Analysis." Industrial \& Labor Relations Review 47(1): 3-22.

Katz, Lawrence F., and Alan B. Krueger. 1999. "The High-Pressure U.S. Labor Market of the 1990s." Brookings Papers on Economic Activity 1, pp. 1-65.

Kaufman, Roger. 1979. "Why the U.S. Unemployment Rate is So High.” In Unemployment and Inflation: Institutionalist and Structuralist Views, edited by M.J.Piore. White Plains, N. Y.: M.E.Sharpe, pp. 168.

Korenman, Sanders, and David Neumark. 2000. "Cohort Crowding and Youth Labor Markets: A Cross-National Analysis," In Youth Employment and Joblessness in Advanced Countries, edited by David G. Blanchflower and Richard B. Freeman. Chicago: University of Chicago Press, pp. 57-105.

Krueger, Alan B., and Jörn-Steffen Pischke. 1997. "Observations and Conjectures on the U.S. Employment Miracle." Working Paper 390. Princeton University Industrial Relations Section, August 1997.

Layard, Richard, Stephen Nickell, and Richard Jackman. 1991. Unemployment. Oxford: Oxford University Press.

Ljungqvist, Lars, and Thomas J. Sargent. 1998. "The European Unemployment Dilemma." Journal of Political Economy 106(3): pp. 514-50.

Maloney, Tim. 1994. "Estimating the Effects of the Employment Contracts Act on Employment and Wages in New Zealand." Australian Bulletin of Labour 20(4): 320-43.

Mankiw, N. Gregory. "Comments and Discussion." [on Ball 1999]. 1999. Brookings Papers on Economic Activity 2: 237-241.

Nickell, Stephen. 1997. "Unemployment and Labor Market Rigidities: Europe versus North America." The Journal of Economic Perspectives 11(3): 55-74. 
, and Richard Layard. 1999. "Labor Market Institutions and Economic Performance." In Handbook of Labor Economics, Volume 3C, edited by Orley Ashenfelter and David Card. Amsterdam: North-Holland, pp. 3029-3084.

Nickell, Steve, and Jan van Ours. 2000 "The Netherlands and the United Kingdom: a European unemployment miracle?” Economic Policy (no. 30): 137-180.

OECD. 1990. Employment Outlook July 1990. Paris: OECD.

OECD. 1994a. Employment Outlook July 1994. Paris: OECD.

OECD. 1994b. The OECD Jobs Study: Evidence and Explanations. Paris: OECD.

OECD. 1996. Employment Outlook July 1996. Paris: OECD.

OECD. 1998a. Employment Outlook July 1998. Paris: OECD.

OECD. 1998b. Purchasing Power Parities and Real Expenditures. Paris: OECD.

OECD. 1999. Employment Outlook June 1999. Paris: OECD.

OECD. 2000. Employment Outlook June 2000. Paris: OECD.

Oliner, Stephen D., and Daniel E. Sichel. 2000. "The Resurgence of Growth in the Late 1990s: Is Information Technology the Story?" Unpublished paper. Washington, DC: Federal Reserve Board of Governors.

Pelling, Henry. 1960. American Labor. Chicago, IL: University of Chicago Press.

Shimer, Robert. 1998. "Why is the U.S. Unemployment Rate So Much Lower?” In NBER Macroeconomics Annual 1998. Cambridge, Mass.: MIT Press, pp. 11-61.

-----------. 1999. “The Impact of Young Workers on the Aggregate Labor Market.” Working Paper 7306. Cambridge, Mass.: National Bureau of Economic Research, August.

Siebert, Horst. 1997. "Labor Market Rigidities: At the Root of Unemployment in Europe." Journal of Economic Perspectives 11(3): 37-54.

Sorrentino, Constance. 2000. "International Unemployment Rates: How Comparable Are They?" Monthly Labor Review 123(6): 3-20.

Thurow, Lester C. 1985. "Introduction." In The Management Challenge: Japanese Views, edited by L.C.Thurow. Cambridge, MA: MIT Press, pp.9-10.

Visser, Jelle. 1996. "Unionisation Trends Revisited.” Research Paper 1996/2. Amsterdam: Centre for Research of European Societies and Industrial Relations, February.

Wyplosz, Charles. 1997. "EMU: Why and How It Might Happen." Journal of Economic Perspectives 11(4): 3-21. 


\section{$\underline{\text { Data Appendix }}$}

This paper's data set is based on that constructed by Blanchard and Wolfers (2000), documented at http://econ-wp.mit.edu/RePEc/2000/blanchar/harry data/. The data set contains macroeconomic and institutional data on 26 OECD-countries for 8 five-year periods covering the time span 1960-1999.

We have added data on wage distributions, labor force by age groups, labor force by sector, population by age groups, and unemployment rates by age groups for male and female workers separately. We have also included additional labor market institutions indicators.

Wage level and inequality data were constructed from data found in the OECD-database (the data are those published in OECD Employment Outlook, but the file we have is more comprehensive). We calculated the upper bound of the $10^{\text {th }}, 50^{\text {th }}$ and $90^{\text {th }}$ percentile of the wage distribution for each country and year available and use the arithmetic mean of each 5-year period as the indicator for wage inequality. The name format of the inequality variables is $\mathbf{p x x g}$ for the upper bound of $\mathbf{x x}^{\text {th }}$ wage distribution for gender $\mathbf{g}(\mathrm{m}=$ male, $\mathrm{f}=$-female) .

The labor force and population data are taken directly from the ILO database "Economically Active Population 1950-2010". The name format of the labor force and population data is vv(v)gcccc where

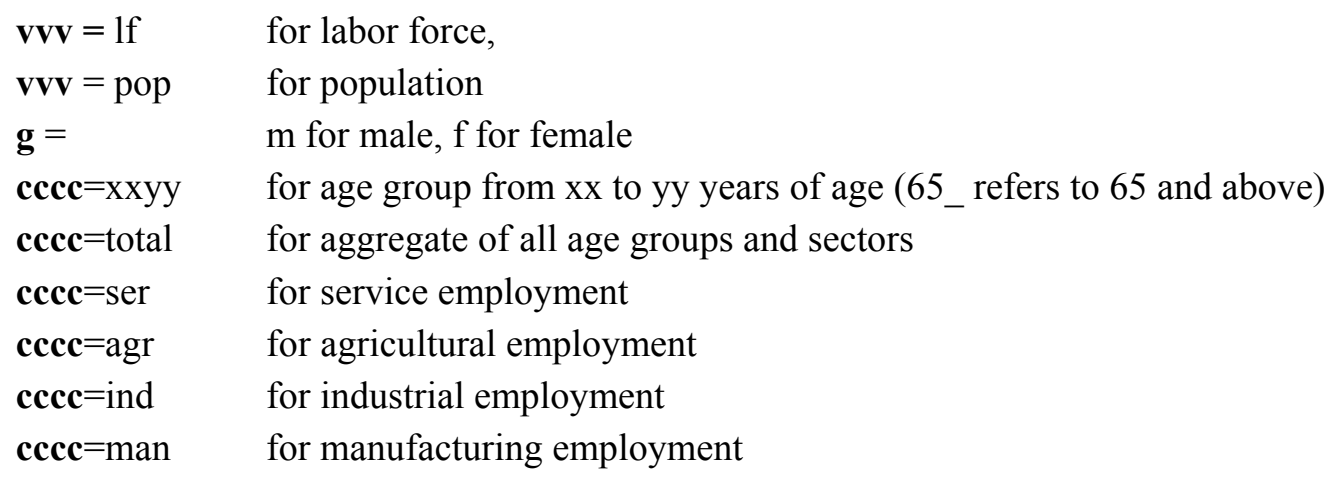

The data on unemployment rates by age group have been constructed from data found in the OECD-publication "Labor Force Survey: Part III". These are country-source data, and we did not attempt to harmonize their definition. To compute the average unemployment rate for each 5 year period we calculate the arithmetic mean of the yearly unemployment rates within the period. To obtain similar data on as many countries as possible, we also aggregate the data to broad age groups by computing the labor force weighted average of the time-averaged unemployment rate of the relevant age groups. The labor force weights themselves are constructed as linearly interpolated weights from the labor force data used above. The name format of the unemployment data is urgxxyy where $\mathbf{g}=\mathrm{m}$ (male) or $\mathrm{f}$ (female), and $\mathbf{x x y y}=$ age group from $\mathbf{x x}$ to yy years of age (55_refers to 55 and above).

The measures for the labor market institutions are taken from the OECD-publication OECD Employment Outlook 1996 and Nickell (1997) with the exception of the collective bargaining coverage (cbcov90) variable. Nickell's (1997) variable, which was used by Blanchard and Wolfers (2000), took on only 3 values. We have replaced it by the more accurate continuous variable reported in OECD (1994a). 


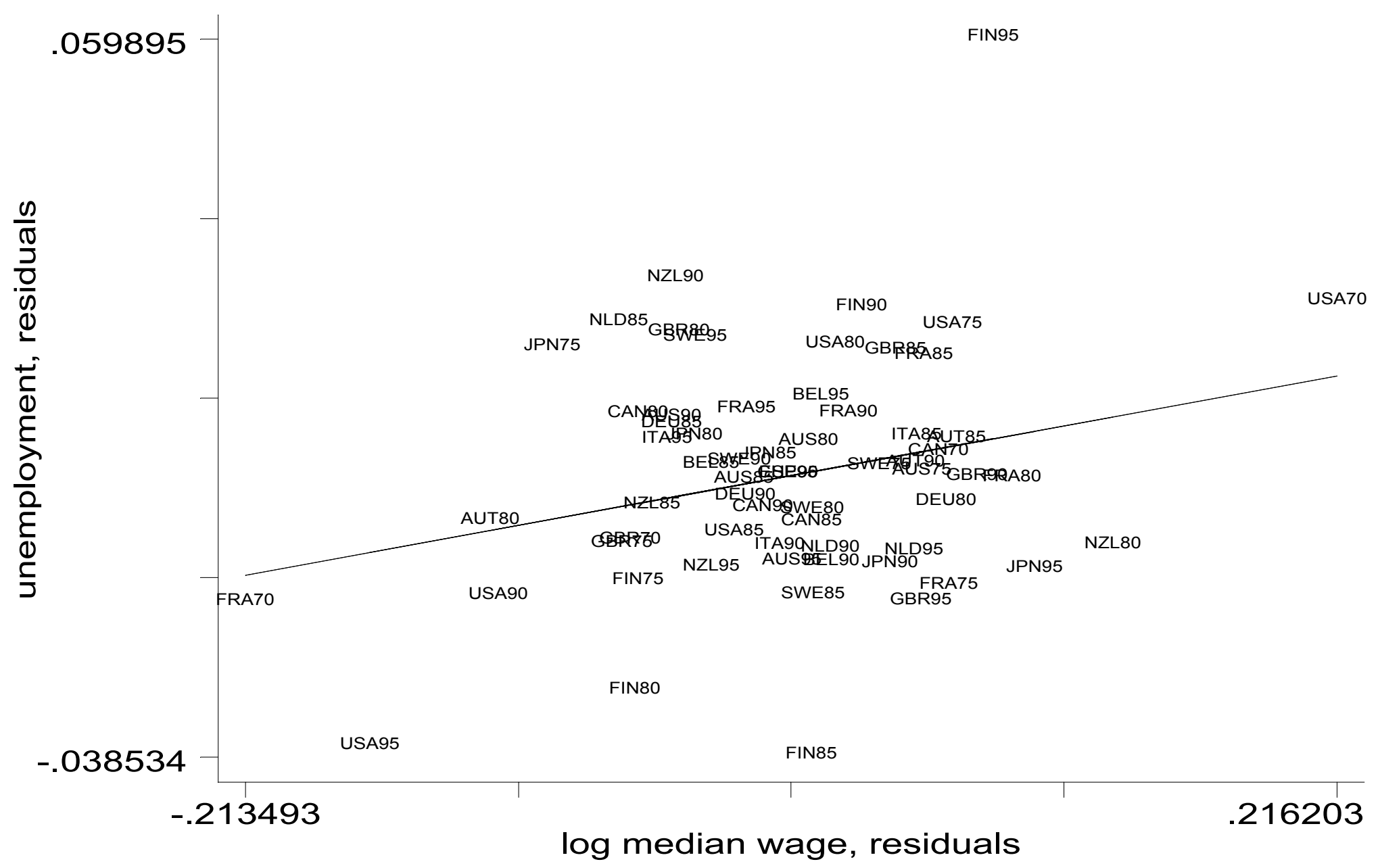

Figure 1: Unemployment Rate and Median Log Male Real Wage (PPP Corrected in US 1998 Dollars) for Fulltime Workers, After Removing Country and Period Effects. The slope $t$ coefficient, 2.416 , is significant at better than $2 \%$. 


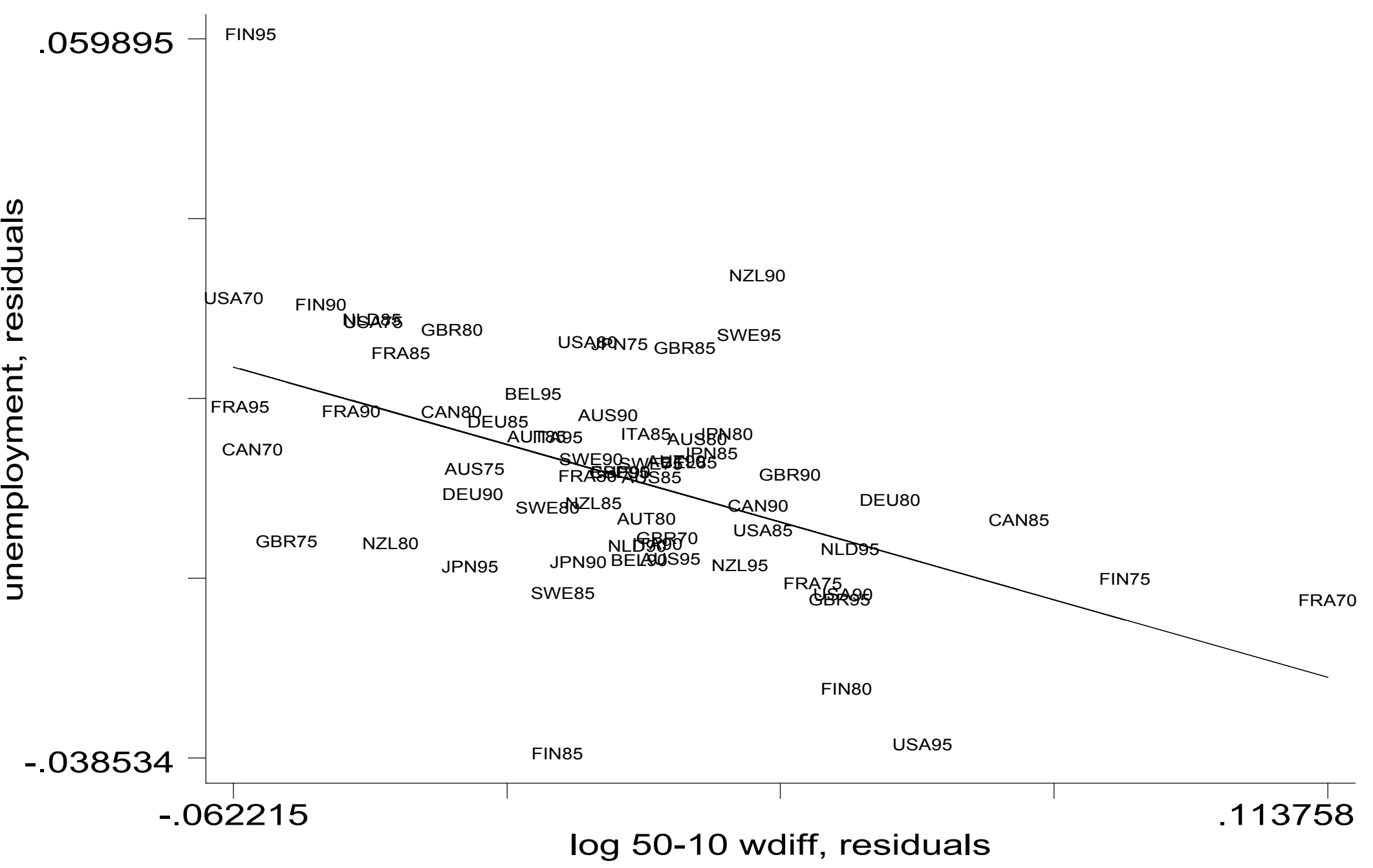

Figure 2: Unemployment and 50-10 Differential, Male Log Weekly Earnings for Fulltime Workers, After Removing Country and Period Effects (slope $\mathrm{t}=4.820$ ) 
Table 1: Overall Unemployment Rate (common definition), Selected Countries

\begin{tabular}{lrr}
\hline \multirow{2}{*}{ Country } & \multicolumn{2}{c}{ Period } \\
\cline { 2 - 3 } \multicolumn{1}{c}{$1970-74$} & $1995-6$ \\
\hline AUSTRALIA & $2.21 \%$ & $8.54 \%$ \\
BELGIUM & $2.21 \%$ & $14.23 \%$ \\
CANADA & $5.83 \%$ & $9.61 \%$ \\
FINLAND & $2.15 \%$ & $16.74 \%$ \\
FRANCE & $2.71 \%$ & $11.54 \%$ \\
ITALY & $4.27 \%$ & $12.04 \%$ \\
JAPAN & $1.30 \%$ & $3.24 \%$ \\
NETHERLANDS & $1.79 \%$ & $7.11 \%$ \\
NEW ZEALAND & $0.23 \%$ & $6.20 \%$ \\
SPAIN & $2.97 \%$ & $22.96 \%$ \\
SWEDEN & $2.24 \%$ & $7.87 \%$ \\
UK & $2.53 \%$ & $7.88 \%$ \\
& & \\
NON-US Average (unweighted) & $2.54 \%$ & $10.66 \%$ \\
USA & $5.41 \%$ & $5.50 \%$ \\
\hline
\end{tabular}

Source: Blanchard and Wolfers (2000). 
Table 2: Log Median Male Weekly Earnings, Fulltime Workers, Purchasing-Power Corrected Constant 1998 US Dollars (GDP Personal Consumption Expenditures Deflator)

\begin{tabular}{|c|c|c|c|c|c|}
\hline \multirow[b]{2}{*}{ COUNTRY } & \multicolumn{4}{|c|}{ Level } & \multirow{2}{*}{$\begin{array}{c}\text { Change } \\
1975-9 \text { to } 1995-6 \\
\end{array}$} \\
\hline & $1975-9$ & $1980-4$ & $1990-4$ & $1995-6$ & \\
\hline AUSTRALIA & 6.01 & 6.01 & 6.06 & 6.14 & 0.14 \\
\hline AUSTRIA & . & 5.77 & 6.04 & & . \\
\hline BELGIUM & . & . & 6.13 & 6.17 & . \\
\hline CANADA & . & 6.25 & 6.40 & . & . \\
\hline FINLAND & 5.85 & 5.89 & 6.08 & 6.17 & 0.33 \\
\hline FRANCE & 5.64 & 5.71 & 5.75 & 5.75 & 0.11 \\
\hline GERMANY & . & 6.26 & 6.29 & 6.36 & . \\
\hline ITALY & . & . & 6.03 & 6.02 & . \\
\hline JAPAN & 5.66 & 5.76 & 5.94 & 6.04 & 0.38 \\
\hline NETHERLANDS & . & . & 6.21 & 6.28 & . \\
\hline NEW ZEALAND & . & 6.11 & 6.05 & 6.10 & . \\
\hline SPAIN & . & . & . & 5.98 & . \\
\hline SWEDEN & 5.96 & 5.98 & 6.06 & 6.08 & 0.11 \\
\hline SWITZERLAND & . & . & 6.49 & 6.53 & . \\
\hline UK & 5.92 & 5.99 & 6.21 & 6.23 & 0.31 \\
\hline $\begin{array}{l}\text { Non-US Average (current year } \\
\text { sample) }\end{array}$ & 5.84 & 5.97 & 6.13 & 6.14 & . \\
\hline $\begin{array}{l}\text { Non-US Average (1975-9 } \\
\text { sample) }\end{array}$ & 5.84 & 5.89 & 6.02 & 6.07 & 0.23 \\
\hline USA & 6.37 & 6.37 & 6.34 & 6.33 & -0.04 \\
\hline
\end{tabular}

Source: Unpublished OECD data. 
Table 3: 50-10 Differential in Male Log Weekly Earnings, Fulltime Workers

\begin{tabular}{|c|c|c|c|c|c|}
\hline COUNTRY & $1975-9$ & $1980-4$ & $1990-4$ & $1995-6$ & $1975-9$ to $1995-6$ \\
\hline AUSTRALIA & 0.45 & 0.49 & 0.50 & 0.52 & 0.07 \\
\hline AUSTRIA & . & 0.49 & 0.51 & & \\
\hline BELGIUM & . & . & 0.33 & 0.32 & ${ }^{\circ}$ \\
\hline CANADA & . & 0.73 & 0.80 & . & . \\
\hline FINLAND & 0.48 & 0.44 & 0.38 & 0.38 & -0.10 \\
\hline FRANCE & 0.52 & 0.49 & 0.48 & 0.47 & -0.05 \\
\hline GERMANY & . & 0.42 & 0.38 & 0.38 & \\
\hline ITALY & . & . & 0.35 & 0.34 & \\
\hline JAPAN & 0.46 & 0.48 & 0.48 & 0.47 & 0.02 \\
\hline NETHERLANDS & . & . & 0.41 & 0.45 & . \\
\hline NEW ZEALAND & . & 0.49 & 0.57 & 0.58 & $\cdot$ \\
\hline SPAIN & . & . & . & 0.67 & . \\
\hline SWEDEN & 0.28 & 0.27 & 0.30 & 0.34 & 0.06 \\
\hline SWITZERLAND & . & . & 0.40 & 0.41 & . \\
\hline UK & 0.46 & 0.50 & 0.58 & 0.59 & 0.13 \\
\hline $\begin{array}{l}\text { Non-US Average (current } \\
\text { year sample) }\end{array}$ & 0.44 & 0.48 & 0.46 & 0.45 & 0.01 \\
\hline $\begin{array}{l}\text { Non-US Average (1975-9 } \\
\text { sample) }\end{array}$ & 0.44 & 0.45 & 0.45 & 0.46 & 0.02 \\
\hline USA & 0.66 & 0.71 & 0.77 & 0.79 & 0.13 \\
\hline
\end{tabular}

Source: Unpublished OECD data. 
Table 4: Mean Values of Key Variables: Blanchard-Wolfers Sample, Countries with Complete Observations in 1970-74 and 1995-96

\begin{tabular}{|c|c|c|c|c|c|c|c|}
\hline & \multicolumn{2}{|c|}{1970} & \multicolumn{2}{|c|}{1995} & \multicolumn{2}{|c|}{$\begin{array}{c}\text { Change: } 1970 \text { to } \\
1995\end{array}$} & \multirow{2}{*}{$\begin{array}{c}\text { Difference in } \\
\text { Change: } \\
\text { NONUS-US }\end{array}$} \\
\hline & NONUS & US & NONUS & US & NONUS & US & \\
\hline Unem Rate & 0.0254 & 0.0541 & 0.1066 & 0.0550 & 0.0813 & 0.0009 & 0.0804 \\
\hline Labor Demand & 0.0013 & 0.0046 & 0.0501 & 0.0697 & 0.0488 & 0.0651 & -0.0163 \\
\hline Real Interest Rate & 0.0152 & 0.0196 & 0.0529 & 0.0389 & 0.0378 & 0.0192 & 0.0185 \\
\hline TFP & -0.0370 & -0.0087 & -0.0082 & -0.0015 & 0.0289 & 0.0072 & 0.0216 \\
\hline Change in Inflation & -0.0043 & -0.0037 & 0.0027 & 0.0009 & 0.0070 & 0.0046 & 0.0023 \\
\hline UI Rep. Rate & 54.1667 & 50.0000 & 54.1667 & 50.0000 & 0.0000 & 0.0000 & 0.0000 \\
\hline UI Duration & 2.6521 & 0.5000 & 2.6521 & 0.5000 & 0.0000 & 0.0000 & 0.0000 \\
\hline Cbcov90 & 69.7500 & 18.0000 & 69.7500 & 18.0000 & 0.0000 & 0.0000 & 0.0000 \\
\hline Emp. protection & 10.5000 & 1.0000 & 10.5000 & 1.0000 & 0.0000 & 0.0000 & 0.0000 \\
\hline Almphat & -12.2783 & -2.5900 & -12.2783 & -2.5900 & 0.0000 & 0.0000 & 0.0000 \\
\hline Union Density & 41.3458 & 17.3000 & 41.3458 & 17.3000 & 0.0000 & 0.0000 & 0.0000 \\
\hline Labor Tax Rate & 49.7583 & 43.2000 & 49.7583 & 43.2000 & 0.0000 & 0.0000 & 0.0000 \\
\hline Coord & -3.6667 & -2.0000 & -3.6667 & -2.0000 & 0.0000 & 0.0000 & 0.0000 \\
\hline
\end{tabular}

Note: all variables are signed so that they are expected to have a positive effect on unemployment. (labor demand, tfp, change in inflation, almphat, and coord all have been multiplied by -1). Non-US countries include: Australia, Belgium, Canada, Finland, France, Italy, Japan, Netherlands, New Zealand, Spain, Sweden, UK. 
Table 5: OLS Regression Results: Original Blanchard-Wolfers Sample (1960-95)

\section{Dependent Variable=Unemployment Rate}

\begin{tabular}{|c|c|c|c|c|}
\hline Explanatory Variables & coef & std err & coef & std err \\
\hline Labor Demand & 0.169 & 0.070 & 0.143 & 0.061 \\
\hline Real Interest Rate & 0.610 & 0.113 & 0.235 & 0.152 \\
\hline TFP & 0.309 & 0.147 & -0.230 & 0.146 \\
\hline Change in Inflation & 2.331 & 0.626 & 1.049 & 0.577 \\
\hline \multicolumn{5}{|c|}{$\begin{array}{l}\text { Country Dummies (including post-Portugal } \\
\text { revolution) }\end{array}$} \\
\hline Year Dummies & no & & yes & $\mathrm{p}<.001$ \\
\hline $\mathrm{R} 2$ & 0.6971 & & 0.8092 & \\
\hline Sample Size & 131 & & 131 & \\
\hline rho-AR1 (std err) & 0.317 & 0.085 & 0.577 & 0.083 \\
\hline \multicolumn{5}{|c|}{ Actual unemp rate change $1970-95$ : } \\
\hline United States & 0.0009 & & 0.0009 & \\
\hline Common Non-US Sample & 0.0813 & & 0.0813 & \\
\hline \multicolumn{5}{|c|}{ Predicted unemp rate change $1970-95:$} \\
\hline United States & 0.0358 & & 0.0758 & \\
\hline Common Non-US Sample & 0.0564 & & 0.0753 & \\
\hline \multicolumn{5}{|l|}{ Percent of US-Other Country } \\
\hline $\begin{array}{l}\text { Difference in 1970-95 unemp } \\
\text { rate Change Explained }\end{array}$ & $25.62 \%$ & & $-0.62 \%$ & \\
\hline
\end{tabular}

Notes: All variables have been signed so that they are expected to raise unemployment, i.e. labor demand, change in inflation and TFP have been multiplied by -1.) Common Non-US Sample includes Australia, Belgium, Canada, Finland, France, Italy, Japan, Netherlands, New Zealand, Spain, Sweden, and UK. Rho is the autocorrelation coefficient. 
Table 6: Mean Values of Key Variables: Youth Sample, Countries with Complete Observations in 1970-74 and 1995-96

\begin{tabular}{|c|c|c|c|c|c|c|c|}
\hline & \multicolumn{2}{|c|}{1970} & \multicolumn{2}{|c|}{1995} & \multicolumn{2}{|c|}{$\begin{array}{c}\text { Change: } 1970 \text { to } \\
1995\end{array}$} & \multirow{2}{*}{$\begin{array}{l}\text { Difference in } \\
\text { Change: } \\
\text { NONUS-US }\end{array}$} \\
\hline & NONUS & US & NONUS & US & NONUS & US & \\
\hline Unem Rate & 0.0291 & 0.0541 & 0.1116 & 0.0550 & 0.0825 & 0.0009 & 0.0816 \\
\hline Labor Demand & 0.0110 & 0.0046 & 0.0567 & 0.0697 & 0.0457 & 0.0651 & -0.0194 \\
\hline Real Interest Rate & 0.0181 & 0.0196 & 0.0539 & 0.0389 & 0.0358 & 0.0192 & 0.0166 \\
\hline TFP & -0.0305 & -0.0087 & -0.0147 & -0.0015 & 0.0158 & 0.0072 & 0.0086 \\
\hline Change in Inflation & -0.0046 & -0.0037 & 0.0022 & 0.0009 & 0.0068 & 0.0046 & 0.0021 \\
\hline Youth Pop Share & 0.2246 & 0.2426 & 0.1702 & 0.1713 & -0.0544 & -0.0713 & 0.0169 \\
\hline $\begin{array}{l}\text { Births/Pop 15-24 Years } \\
\text { Ago }\end{array}$ & 0.0209 & 0.0248 & 0.0155 & 0.0154 & -0.0054 & -0.0093 & 0.0040 \\
\hline UI Rep. Rate & 54.0000 & 50.0000 & 54.0000 & 50.0000 & 0.0000 & 0.0000 & 0.0000 \\
\hline UI Duration & 2.3139 & 0.5000 & 2.3139 & 0.5000 & 0.0000 & 0.0000 & 0.0000 \\
\hline Cbcov90 & 67.6667 & 18.0000 & 67.6667 & 18.0000 & 0.0000 & 0.0000 & 0.0000 \\
\hline Emp. protection & 10.8889 & 1.0000 & 10.8889 & 1.0000 & 0.0000 & 0.0000 & 0.0000 \\
\hline Almphat & -13.7578 & -2.5900 & -13.7578 & -2.5900 & 0.0000 & 0.0000 & 0.0000 \\
\hline Union Density & 40.9111 & 17.3000 & 40.9111 & 17.3000 & 0.0000 & 0.0000 & 0.0000 \\
\hline Labor Tax Rate & 50.6056 & 43.2000 & 50.6056 & 43.2000 & 0.0000 & 0.0000 & 0.0000 \\
\hline Coord & -3.6667 & -2.0000 & -3.6667 & -2.0000 & 0.0000 & 0.0000 & 0.0000 \\
\hline
\end{tabular}

Note: all variables are signed so that they are expected to have a positive effect on unemployment. E.G.: labor demand, tfp, change in inflation, almphat, and coord all have been multiplied by -1 .

Non-US countries include: Australia, Canada, Finland, France, Italy, Japan, Spain, Sweden, and UK. 
Table 7: OLS Regression Results: Youth Sample

\begin{tabular}{|c|c|c|c|c|}
\hline Explanatory Variables & coef & std err & coef & std err \\
\hline Labor Demand & 0.299 & 0.088 & 0.197 & 0.091 \\
\hline Real Interest Rate & 0.519 & 0.122 & 0.295 & 0.187 \\
\hline TFP & 0.102 & 0.183 & -0.308 & 0.187 \\
\hline Change in Inflation & 2.356 & 0.652 & 1.455 & 0.633 \\
\hline Youth Pop Share & ---- & ---- & ---- & ---- \\
\hline Country Dummies (including post-Portugal revolution) & yes & & yes & \\
\hline Year Dummies & no & & yes & $\mathrm{p}<.001$ \\
\hline $\mathrm{R} 2$ & 0.7274 & & 0.811 & \\
\hline Sample Size & 103 & & 103 & \\
\hline rho-AR1 (std err) & 0.218 & 0.096 & 0.471 & 0.102 \\
\hline \multicolumn{5}{|l|}{ Actual unemp rate change 1970-95: } \\
\hline United States & 0.0009 & & 0.0009 & \\
\hline Common Non-US Sample & 0.0825 & & 0.0825 & \\
\hline \multicolumn{5}{|l|}{ Predicted unemp rate change 1970-95: } \\
\hline United States & 0.0411 & & 0.0745 & \\
\hline Common Non-US Sample & 0.0498 & & 0.0760 & \\
\hline \multicolumn{5}{|l|}{ Percent of US-Other Country } \\
\hline $\begin{array}{l}\text { Difference in 1970-95 unemp } \\
\text { rate Change Explained }\end{array}$ & $10.66 \%$ & & $1.84 \%$ & \\
\hline
\end{tabular}

Notes: All variables have been signed so that they are expected to raise unemployment (i.e. labor demand, change in inflation and TFP have been multiplied by -1). Common Non-US Sample Includes Australia, Canada, Finland, France, Italy, Japan, Spain, Sweden, and UK. Rho is the residual autocorrelation coefficient. 
Table 8: OLS Regression Results: Youth Sample

\section{Dependent Variable=Unemployment Rate}

\begin{tabular}{|c|c|c|c|c|c|c|c|c|}
\hline Explanatory Variables & coef & std err & coef & std err & coef & std err & coef & std err \\
\hline Labor Demand & 0.302 & 0.090 & 0.141 & 0.088 & 0.291 & 0.094 & 0.194 & 0.085 \\
\hline Real Interest Rate & 0.529 & 0.134 & 0.308 & 0.176 & 0.508 & 0.130 & 0.294 & 0.175 \\
\hline TFP & 0.110 & 0.189 & -0.200 & 0.179 & 0.085 & 0.196 & -0.190 & 0.178 \\
\hline Change in Inflation & 2.359 & 0.656 & 1.212 & 0.600 & 2.354 & 0.656 & 1.249 & 0.594 \\
\hline Youth Pop Share & 0.028 & 0.152 & 0.550 & 0.169 & ---- & ---- & ---- & ---- \\
\hline (Births/Population) 15-24 yrs earlier & ---- & ---- & ---- & ---- & -0.347 & 1.340 & 4.843 & 1.408 \\
\hline $\begin{array}{l}\text { Country Dummies (including post- } \\
\text { Portugal revolution) }\end{array}$ & yes & & yes & & yes & & yes & \\
\hline Year Dummies & no & & yes & $p<.001$ & no & & yes & $p<.001$ \\
\hline $\mathrm{R} 2$ & 0.7276 & & 0.8349 & & 0.7277 & & 0.8373 & \\
\hline Sample Size & 103 & & 103 & & 103 & & 103 & \\
\hline rho-AR1 (std err) & 0.210 & 0.096 & 0.421 & 0.110 & 0.230 & 0.095 & 0.419 & 0.110 \\
\hline \multicolumn{9}{|l|}{ Actual unemp rate change 1970-95: } \\
\hline United States & 0.0009 & & 0.0009 & & 0.0009 & & 0.0009 & \\
\hline Common Non-US Sample & 0.0825 & & 0.0825 & & 0.0825 & & 0.0825 & \\
\hline \multicolumn{9}{|l|}{ Predicted unemp rate change 1970-95: } \\
\hline United States & 0.0396 & & 0.0625 & & 0.0435 & & 0.0550 & \\
\hline Common Non-US Sample & 0.0489 & & 0.0732 & & 0.0506 & & 0.0765 & \\
\hline \multicolumn{9}{|l|}{ Percent of US-Other Country } \\
\hline $\begin{array}{l}\text { Difference in 1970-95 unemp } \\
\text { rate Change Explained }\end{array}$ & $11.40 \%$ & & $13.11 \%$ & & $8.75 \%$ & & $26.33 \%$ & \\
\hline
\end{tabular}

Notes: All variables have been signed so that they are expected to raise unemployment (i.e. labor demand, change in inflation and TFP) have been multiplied by -1. Non-US Sample with information on 1970-74 and $1995-96$ includes

Australia, Canada, Finland, France, Italy, Japan, Spain, Sweden, and UK. Rho is the residual autocorrelation coefficient. 
Table 9: NLS Regression Results, Shocks and Institutions

Dependent Variable=Unemployment Rate

\begin{tabular}{|c|c|c|c|c|c|c|c|c|}
\hline & coef & std err & coef & std err & coef & std err & coef & std err \\
\hline Labor Demand & 0.123 & 0.083 & 0.046 & 0.051 & 0.110 & 0.080 & 0.031 & 0.037 \\
\hline Real Interest Rate & 0.626 & 0.112 & 0.294 & 0.098 & 0.554 & 0.106 & 0.234 & 0.082 \\
\hline TFP & 0.260 & 0.194 & 0.089 & 0.144 & 0.124 & 0.196 & 0.203 & 0.131 \\
\hline Change in Inflation & 3.061 & 0.623 & 1.443 & 0.530 & 3.043 & 0.597 & 1.061 & 0.419 \\
\hline Youth Pop Share & -0.003 & 0.149 & 0.648 & 0.145 & ---- & ---- & ---- & ---- \\
\hline Births/Pop 15-24 yrs ago & ---- & ---- & ---- & ---- & -2.407 & 1.516 & 4.582 & 1.330 \\
\hline XRRATE & 0.005 & 0.008 & 0.019 & 0.016 & 0.003 & 0.007 & 0.050 & 0.026 \\
\hline XBENEFIT & 0.398 & 0.108 & 0.533 & 0.168 & 0.434 & 0.100 & 0.588 & 0.213 \\
\hline XCB & -0.013 & 0.011 & -0.035 & 0.022 & -0.013 & 0.010 & -0.065 & 0.031 \\
\hline XEMPRO & 0.056 & 0.030 & 0.111 & 0.067 & 0.069 & 0.029 & 0.248 & 0.111 \\
\hline XALMPHAT & 0.008 & 0.011 & -0.028 & 0.021 & 0.004 & 0.010 & 0.004 & 0.027 \\
\hline XUDEN & 0.011 & 0.010 & -0.023 & 0.017 & 0.011 & 0.010 & 0.002 & 0.023 \\
\hline XT & 0.027 & 0.013 & 0.015 & 0.022 & 0.021 & 0.012 & 0.062 & 0.035 \\
\hline XCOORD & 0.307 & 0.176 & 0.341 & 0.245 & 0.286 & 0.153 & 0.743 & 0.375 \\
\hline \multicolumn{9}{|l|}{$\begin{array}{l}\text { Country Dummies (including post- } \\
\text { Portugal revolution) }\end{array}$} \\
\hline Year Dummies & no & & yes & $p<.001$ & no & & yes & $p<.001$ \\
\hline Sample Size & 103 & & 103 & & 103 & & 103 & \\
\hline rho-AR1 (std err) & -0.044 & 0.102 & -0.024 & 0.120 & -0.001 & 0.103 & 0.184 & 0.124 \\
\hline \multicolumn{9}{|l|}{ Actual unemp rate change $1970-95:$} \\
\hline United States & 0.0009 & & 0.0009 & & 0.0009 & & 0.0009 & \\
\hline Common Non-US Sample & 0.0825 & & 0.0825 & & 0.0825 & & 0.0825 & \\
\hline \multicolumn{9}{|c|}{ Predicted unemp rate change 1970-95: } \\
\hline United States & 0.0193 & & 0.0373 & & 0.0189 & & 0.0287 & \\
\hline Common Non-US Sample & 0.0601 & & 0.0765 & & 0.0644 & & 0.0798 & \\
\hline \multicolumn{9}{|l|}{ Percent of US-Other Country } \\
\hline \multicolumn{9}{|l|}{ Difference in 1970-95 unemp } \\
\hline Rate Change Explained & $50.00 \%$ & & $48.04 \%$ & & $55.72 \%$ & & $62.67 \%$ & \\
\hline
\end{tabular}

Notes: All variables have been signed so that they are expected to raise unemployment (i.e. labor demand And TFP have been multiplied by -1 . Institutional variables are: RRATE=UI replacement rate; BENEFIT= $\mathrm{UI}$ benefit duration (4=indefinite); $\mathrm{CB}=$ continuous measure of coll. barg. coverage; $E M P R O=e m p l o y m e n t$ protection rank; ALMPHAT=instrumented ALMP measure; UDEN=union density; T=labor tax rate; COORD= coordination rank. NLS=nonlinear least squares model (linear combination of shocks) $)^{*}$ (each institution) Rho=autocorrelation coefficient. 
Table 10: Group-Specific Employment-to-Population Ratios and Unemployment Rates: Youth Sample

\begin{tabular}{lrrrrrrr}
\hline & \multicolumn{1}{c}{1970} & & & & \multicolumn{2}{c}{ Change } & \multicolumn{2}{c}{$\begin{array}{c}\text { Difference } \\
\text { in Change }\end{array}$} \\
\cline { 2 - 8 } & NONUS & US & NONUS & US & NONUS & US & NONUS-US \\
\hline Overall Unem Rate & 0.029 & 0.054 & 0.112 & 0.055 & 0.082 & 0.001 & 0.082 \\
Unem Rate: men 15-24 & 0.057 & 0.100 & 0.209 & 0.122 & 0.152 & 0.022 & 0.131 \\
Unem Rate: men 25-54 & 0.019 & 0.029 & 0.087 & 0.041 & 0.068 & 0.012 & 0.056 \\
Unem Rate: men 55+ & 0.025 & 0.029 & 0.082 & 0.034 & 0.058 & 0.005 & 0.053 \\
Unem Rate: women 15-24 & 0.052 & 0.118 & 0.239 & 0.111 & 0.188 & -0.007 & 0.195 \\
Unem Rate: women 25-54 & 0.018 & 0.048 & 0.107 & 0.044 & 0.089 & -0.005 & 0.094 \\
Unem Rate: women 55+ & 0.014 & 0.033 & 0.069 & 0.033 & 0.055 & 0.000 & 0.055 \\
Epop: men 15-24 & 0.673 & 0.585 & 0.463 & 0.536 & -0.210 & -0.049 & -0.161 \\
Epop: men 25-54 & 0.943 & 0.931 & 0.860 & 0.883 & -0.083 & -0.048 & -0.035 \\
Epop: men 55+ & 0.510 & 0.530 & 0.302 & 0.355 & -0.208 & -0.175 & -0.034 \\
Epop: women 15-24 & 0.492 & 0.400 & 0.412 & 0.496 & -0.080 & 0.096 & -0.176 \\
Epop: women 25-54 & 0.461 & 0.474 & 0.652 & 0.734 & 0.191 & 0.260 & -0.069 \\
Epop: women 55+ & 0.181 & 0.236 & 0.144 & 0.208 & -0.037 & -0.028 & -0.009 \\
Ln(epop men 2554/epop women & & & & & & & \\
2554) & 0.755 & 0.675 & 0.299 & 0.184 & -0.456 & -0.491 & 0.035 \\
Ln(epop 2554/epop1524) men & 0.342 & 0.464 & 0.642 & 0.499 & 0.301 & 0.035 & 0.266 \\
Ln(epop 2554/epop55+) men & 0.628 & 0.564 & 1.097 & 0.910 & 0.469 & 0.346 & 0.122 \\
Ln(epop 2554/epop1524) women & -0.093 & 0.171 & 0.498 & 0.393 & 0.591 & 0.222 & 0.368 \\
Ln(epop 2554/epop55+) women & 0.966 & 0.696 & 1.586 & 1.261 & 0.620 & 0.565 & 0.054 \\
\hline
\end{tabular}

Non-US countries include: Australia, Canada, Finland, France, Italy, Japan, Spain, Sweden, UK. Epop is the employment to population ratio. These data are computed from country-specific labor market indicators and interpolated ILO population series (see the data appendix for details). 
Table 11: Mean Values of Key Variables: updated Blanchard-Wolfers Sample, countries with complete observations in 1990-94 and 1995-98/99; and US in 1995-99

\begin{tabular}{|c|c|c|c|c|c|c|c|}
\hline & \multicolumn{2}{|c|}{$1990-94$} & \multicolumn{2}{|c|}{$1995-98$ or 99} & \multicolumn{2}{|l|}{ Change } & $\begin{array}{l}\text { Difference } \\
\text { in Change }\end{array}$ \\
\hline & NONUS & US & NONUS & US & NONUS & \multicolumn{2}{|c|}{ USNONUS-US } \\
\hline Unem Rate & 0.0939 & 0.0659 & 0.0934 & 0.0494 & -0.0005 & -0.0165 & 0.0160 \\
\hline Labor Demand & 0.0398 & 0.0693 & 0.0488 & 0.0682 & 0.0090 & -0.0011 & 0.0101 \\
\hline Real Interest Rate & 0.0524 & 0.0401 & 0.0393 & 0.0398 & -0.0131 & -0.0003 & -0.0128 \\
\hline TFP & -0.0179 & -0.0172 & -0.0197 & -0.0210 & -0.0018 & -0.0038 & 0.0020 \\
\hline Change in Inflation & 0.0019 & 0.0006 & -0.0001 & 0.0005 & -0.0020 & -0.0001 & -0.0019 \\
\hline Youth Pop Share & 0.1875 & 0.1844 & 0.1715 & 0.1713 & -0.0160 & -0.0131 & -0.0029 \\
\hline Births/Pop 15-24 yrs ago & 0.0160 & 0.0160 & 0.0153 & 0.0154 & -0.0007 & -0.0006 & -0.0001 \\
\hline \multirow[t]{3}{*}{ Predicted Unem Rate* } & 0.0963 & 0.0687 & 0.0879 & 0.0688 & -0.0084 & 0.0001 & -0.0085 \\
\hline & \multicolumn{5}{|c|}{ Recent Developments in the US: } & & \\
\hline & 1995 & 1996 & 1997 & 1998 & 1999 & & \\
\hline Unem Rate & 0.0560 & 0.0540 & 0.0494 & 0.0451 & 0.0425 & & \\
\hline Labor Demand & 0.0667 & 0.0690 & 0.0690 & 0.0695 & 0.0705 & & \\
\hline Real Interest Rate & 0.0409 & 0.0425 & 0.0427 & 0.0348 & 0.0380 & & \\
\hline TFP & -0.0040 & -0.0298 & -0.0292 & -0.0357 & -0.0206 & & \\
\hline Change in Inflation & 0.0001 & -0.0012 & -0.0006 & -0.0004 & -0.0003 & & \\
\hline Predicted Unem Rate** & 0.0695 & 0.0670 & 0.0678 & 0.0659 & 0.0676 & & \\
\hline
\end{tabular}

Note: all variables are signed so that they are expected to have a positive effect on unemployment.

E.G.: labor demand, tfp, change in inflation, almphat, and coord all have been multiplied by -1 .

Non-US countries include: Belgium, Canada, Denmark, Finland, France, Germany, Ireland, Italy, Japan, Netherlands, New Zealand, Norway, Spain, Sweden, UK.

*Model includes shocks, country dummies, Portugal revolution dummy, births/pop and institutions; original Blanchard-Wolfers augmented data used to estimate the model.

** This prediction is based on the same regression model used earlier in this Table and assuming no demographic change. 
Table 12: United States Unemployment Residuals from Equations with Shocks and Institutions

\begin{tabular}{lcccc}
\hline & \multicolumn{4}{c}{ Specification } \\
\cline { 2 - 5 } & \multicolumn{2}{c}{ Youth Share } & Prior Births/Prior Population \\
\cline { 2 - 5 } Period & $\begin{array}{c}\text { Without Period } \\
\text { Effects }\end{array}$ & $\begin{array}{c}\text { With Period } \\
\text { Effects }\end{array}$ & $\begin{array}{c}\text { Without Period } \\
\text { Effects }\end{array}$ & $\begin{array}{c}\text { With Period } \\
\text { Effects }\end{array}$ \\
\hline $1965-69$ & -0.0154 & 0.0079 & -0.0144 & 0.0019 \\
$1970-74$ & 0.0033 & 0.0122 & 0.0049 & 0.0081 \\
$1975-79$ & 0.0139 & 0.0003 & 0.0158 & 0.0018 \\
$1980-84$ & 0.0093 & -0.0148 & 0.0155 & 0.0025 \\
$1985-89$ & -0.0064 & -0.0191 & -0.0052 & -0.0098 \\
$1990-94$ & -0.0005 & 0.0011 & -0.0028 & 0.0018 \\
$1995-99$ & -0.0161 & -0.0238 & -0.0194 & -0.0212 \\
\hline
\end{tabular}

Note: Country dummies and Portuguese revolution dummy also included.

Equations are estimated using the original augmented Blanchard-Wolfers data, and residuals are constructed using the corrected OECD data. 
Table A1: Mean Values for Time-Varying Institutions

\begin{tabular}{|c|c|c|c|c|c|c|}
\hline & \multicolumn{3}{|c|}{ Non-US } & \multicolumn{3}{|c|}{ US } \\
\hline & 1970 & 1995 & Diff: $1995-1970$ & 1970 & 1995 & $\begin{array}{c}\text { Diff: } 1995- \\
1970\end{array}$ \\
\hline UI Replacement Rate (1 yr) & 32.41 & 49.30 & 16.89 & 23.74 & 26.92 & 3.18 \\
\hline Employment Protection Index & 2.06 & 2.13 & 0.07 & 0.20 & 0.20 & 0.00 \\
\hline Collective Bargaining Coverage & 72.22 & 69.22 & -3.00 & 26.00 & 18.00 & -8.00 \\
\hline Union Density & 40.65 & 40.58 & -0.07 & 26.45 & 15.28 & -11.17 \\
\hline Coordination & -1.97 & -1.92 & 0.06 & -1.00 & -1.00 & 0.00 \\
\hline
\end{tabular}

Sources: UI Replacement Rate and Employment Protection Index: Blanchard and Wolfers (2000);

Collective Bargaining Coverage and Coordination: OECD (1997)--original data included only 1980, 1990 and 1994. 1980 values (or earliest available) assigned to 1970 and 1994 values assigned to 1995 .

Union Density: Visser (1996); original data spanned 1970 to 1994, and the earliest values were assigned to 1970 , while the latest values were assigned to 1995.

Non-US countries include: Australia, Canada, Finland, France, Italy, Japan, Spain, Sweden, and UK. 
Table A2: Selected Results for Unemployment Regression Models with Time-Varying Institutions

\begin{tabular}{lrrrr}
\hline & \multicolumn{2}{c}{$\begin{array}{c}\text { OLS Model } \\
\text { Coeff }\end{array}$} & Std Err & \multicolumn{2}{c}{ NLS Model } \\
& & & & \\
Main Effects & & & & \\
& & & & \\
Labor Demand & 0.3093 & 0.0978 & 0.1763 & 0.0612 \\
Real Interest Rate & 0.4242 & 0.1408 & 0.3828 & 0.1179 \\
TFP & 0.1735 & 0.2087 & 0.0529 & 0.1317 \\
Change in Inflation & 1.9540 & 0.6721 & 2.3455 & 0.6871 \\
Births/Pop 15-24 yrs ago & 0.8599 & 1.3967 & 1.9944 & 1.1261 \\
UI Replacement Rate (1 yr) & 0.0007 & 0.0003 & 0.0014 & 0.0003 \\
Collective Bargaining Coverage & -0.0007 & 0.0007 & -0.0012 & 0.0006 \\
Employment Protection Index & -0.0067 & 0.0079 & -0.0184 & 0.0071 \\
Union Density & 0.0006 & 0.0005 & 0.0002 & 0.0005 \\
Coordination & 0.0164 & 0.0196 & 0.0164 & 0.0197 \\
\hline
\end{tabular}

\section{Shock-Institution Interaction Effects}

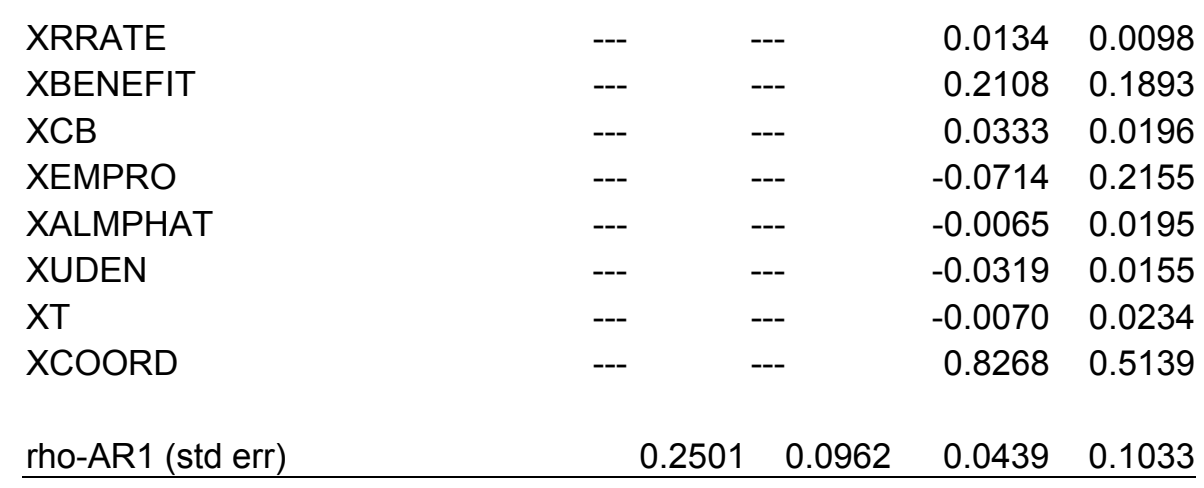

Note: youth sample of 103 observations is used. Equations include country dummies and post-Portuguese revolution dummy but not period effects. 